Illinois State University

ISU ReD: Research and eData

Theses and Dissertations

3-6-2017

\title{
Computer-Mediated Communication Usage and Perceptions Amongst Young Adults with Autism Spectrum Disorder
}

Laura A. Massier

Illinois State University, lamassi@ilstu.edu

Follow this and additional works at: https://ir.library.illinoisstate.edu/etd

Part of the Communication Commons, Special Education Administration Commons, and the Special Education and Teaching Commons

\section{Recommended Citation}

Massier, Laura A., "Computer-Mediated Communication Usage and Perceptions Amongst Young Adults with Autism Spectrum Disorder" (2017). Theses and Dissertations. 696.

https://ir.library.illinoisstate.edu/etd/696

This Dissertation is brought to you for free and open access by ISU ReD: Research and eData. It has been accepted for inclusion in Theses and Dissertations by an authorized administrator of ISU ReD: Research and eData. For more information, please contact ISUReD@ilstu.edu. 
COMPUTER-MEDIATED COMMUNICATION USAGE AND PERCEPTIONS AMONGST

YOUNG ADULTS WITH AUTISM SPECTRUM DISORDER

\title{
124 Pages
}

\author{
Laura A. Massier
}

This was a mixed methods study designed to examine the perceptions of young adults with autism spectrum disorder (ASD) regarding usage of computer-mediated communication (CMC), with a focus on benefits, challenges, and support needs. People with ASD are often prone to social and communication difficulties, making it difficult for them to maintain relationships, find and retain employment, and be active members of their communities. Deficits in these areas are particularly hard for young adults who may no longer have regular routines or opportunities for socializing because they have transitioned out of school-based activities. CMC is a relatively new form of communication, but research suggests its benefits are nearly the same as face-to-face communication for people in the general population. Quantitative and qualitative data obtained from the online survey and interviews indicate overall more perceived benefits than challenges, with suggestions for supports. Overall findings suggest that flexibility in responding is of value to young adults with ASD, while fear of loss of privacy is a challenge in utilizing CMC. Implications for future research include finding ways to help mitigate challenges, and use of explicit instruction regarding CMC tools for those on the spectrum.

KEYWORDS: Autism, Communication, Internet, Young Adults 
YOUNG ADULTS WITH AUTISM SPECTRUM DISORDER

\author{
LAURA A. MASSIER
}

A Dissertation Submitted in Partial

Fulfillment of the Requirements

for the Degree of

DOCTOR OF EDUCATION

Department of Special Education

ILLINOIS STATE UNIVERSITY 
(C) 2017 Laura A. Massier 
Debbie Shelden, Chair

Christina Borders

Lydia Kyei-Blankson

Virginia Walker 


\section{ACKNOWLEDGMENTS}

First and foremost, thank you to Dr. Debbie Shelden whose words of encouragement are eternally etched into my mind. I don't know how you always knew the right thing to say, but you will never know the depth of the impact your kindness has had on me. Thank you also to Drs. Borders, Kyei-Blankson, and Walker for your continuous support of this project, and for helping me take it from a vague idea to a completed study. I am grateful for your guidance. I also want to thank Dr. Thompson for getting me started on this path, which ultimately led to this final destination.

This type of work cannot be done without the support of friends and family; it would have been impossible without the camaraderie of the Chicago cohort. I especially want to thank Dr. Dena Bonnike who answered every text and phone call with a much needed combination of tough love and humor.

I would never have started this degree without the nudge from Natasha Patel, whose friendship and guidance has been a constant in my life. Thank you for listening, reading, and discussing endlessly with me. Likewise, I would never have finished this degree without the support of Colleen Malone, who answered "yes" when asked to sit with me while I did my homework and who would often pepper me with thoughtful questions about what I was learning. Thank you to both of you for cheering me on for so many years. A big thank you is also necessary to Shannon Brown and Deanna Schieler for your friendship and constant offerings to both host and drive me around anytime I was on campus.

This study would not have been possible without the participants, and I'm forever indebted to those who took the time to share it, email it, pilot it, and complete it! A special thank 
you to Julie Tracy, who made it her mission to get the survey distributed as widely as possible. Your friendship has meant more than you'll know.

Thank you to all of my colleagues, and in particular, my bosses, Greg Zurawski and Stephen Laslo, who have been nothing but awesome every time I missed a day of work to go to campus, or asked them to sign off on another project. If it weren't for your good humor and patience, I never would have completed this study.

To my family, I am so thankful for your love and support. I am so appreciative of my wonderful grandparents (and a special shout-out to my grandpa who proofread my proposal) who always ask how my classes are going. I am also grateful for my sister Carolyn, and brother-inlaw Nolan. Our shared experiences have made us who we are, and I am so thankful for you both. I couldn't have done this without my parents, who always encouraged me and have always offered everything they have to help me reach my goals. I love you all very much!

This study would not be a reality without my two best guys. Thank you isn't enough to my husband John who kept me alive and ran the house while I wrote and worried, worried and wrote. Thank you for not letting me quit. Finally, to my brother Matt, without whom there would be no study. You are, simply put, the best ever.

L. A. M. 


\section{CONTENTS}

Page

ACKNOWLEDGMENTS

$\begin{array}{ll}\text { CONTENTS } & \text { iii }\end{array}$

TABLES Di v vi

CHAPTER I: THE PROBLEM AND ITS BACKGROUND 1

ASD and Communication $\quad 4$

Statement of the Problem $\quad 7$

Research Questions $\quad 11$

Definition of Terms $\quad 12$

Chapter Summary 13

CHAPTER II: REVIEW OF RELATED LITERATURE 14

ASD and Social Communication Difficulties 14

$\begin{array}{ll}\text { Interventions } & 17\end{array}$

$\begin{array}{ll}\text { Support groups } & 18\end{array}$

$\begin{array}{ll}\text { Social Capital } & 21\end{array}$

Internet Use and Social Capital 22

Computer Mediated Communication 24

$\begin{array}{ll}\text { CMC Genres } & 26\end{array}$

Discussion/informational groups 26

$\begin{array}{ll}\text { Social networking sites } & 27\end{array}$

$\begin{array}{ll}\text { Online support groups } & 28\end{array}$

Benefits of CMC $\quad 29$

Risks of CMC $\quad 30$

Online Communication and Disability 32

Online Disability Support Groups $\quad 32$

Online Communication and ASD 34 
$\begin{array}{ll}\text { Chapter Summary } & 40\end{array}$

CHAPTER III: RESEARCH METHODS 41

$\begin{array}{ll}\text { The Study } & 41\end{array}$

Design 41

$\begin{array}{ll}\text { Participants } & 42\end{array}$

Qualifying questions $\quad 44$

Participant demographics $\quad 46$

Interview participants $\quad 52$

Ethical Considerations $\quad 53$

Instrumentation $\quad 54$

Data Collection Procedures $\quad 57$

Limitations $\quad 58$

Data Analysis Procedures $\quad 59$

Researcher Positionality and Reflexivity $\quad 60$

Ensuring Reliability and Validity $\quad 61$

$\begin{array}{ll}\text { CHAPTER IV: FINDINGS } & 63\end{array}$

Usage of CMC $\quad 63$

Perceived Benefits of CMC $\quad 71$

Perceived Challenges of CMC $\quad 75$

$\begin{array}{ll}\text { CMC Support Needs } & 78\end{array}$

$\begin{array}{ll}\text { Interviews } & 79\end{array}$

$\begin{array}{ll}\text { Greg } & 80\end{array}$

Steve $\quad 82$

$\begin{array}{ll}\text { Triangulation of Data } & 84\end{array}$

$\begin{array}{ll}\text { CHAPTER V: DISCUSSION } & 86\end{array}$

$\begin{array}{ll}\text { Findings } & 86\end{array}$

$\begin{array}{ll}\text { Benefits } & 86\end{array}$

$\begin{array}{ll}\text { Ease of responding } & 87\end{array}$

Connecting with others $\quad 89$

Special interests 90

Advocacy $\quad 90$ 
Privacy

Disinhibition effect/misinterpretation

Additional drawbacks

Supports

Conclusions

96

Limitations

97

Implications for Future Research

99

Implications for Future Practice

102

REFERENCES

104

APPENDIX A: Informed Consent and Survey Questions

113

APPENDIX B: Informed Consent and Initial Interview Questions

120

APPENDIX C: Interview Questions

123 


\section{TABLES}

Table

Page

1. ASD Diagnosis $\quad 45$

2. Age Range of Study Participants 45

3. Participants' Gender $\quad 47$

4. Participants' Ethnicity 48

5. Participants' Marital Status 49

6. Participants' Living Situation $\quad 50$

7. Participants' Level of Education 51

8. Participants' Employment Status $\quad 52$

9. $\quad$ Reported Usage of CMC Types $\quad 64$

10. Frequency of Various Activities Using CMC in a Two Week Period 66

11. Frequency of Using the Internet to Make Plans or Find Employment in a Two Week Period

12. Frequency of Use of SNSs in a Two Week Period 68

13. Number of SNS Accounts per Participant 69

14. Reported Benefits of Using CMC

15. Challenges of Using CMC 76 


\section{CHAPTER I: THE PROBLEM AND ITS BACKGROUND}

Communication is a fundamental aspect of everyday life. Much of what a person does in a day is dependent on some type of oral, written, or nonverbal communication with others. Communication is a necessary component of working, maintaining relationships, and being a part of one's community. For some people, particularly those with autism spectrum disorder (ASD), communicating with others can be confusing, challenging, or even painful. However, in the past 30 years, the way we communicate has changed dramatically due to the Internet and computer-mediated communication (CMC) (Walther \& Burgoon, 1992). Since its inception, CMC has been studied to determine how this change in the way people communicate affects people's relationships, loneliness, and overall well-being (Ong, Chang, \& Wang, 2011; Sum, Mathews, Pourghasem, \& Hughes, 2008; Walther \& Burgoon, 1992). Computer-mediated communication is defined as a "wide range of technologies that facilitate both human communication and the interactive sharing of information through computer networks, including e-mail, discussion groups, newsgroups, chat, instant messages, and Web pages" (Barnes, 2003, p. 4). As the possible benefits and drawbacks of CMC and Internet communication are examined, what does this mean for people with ASD?

Walther and Burgoon (1992) compared a face-to-face (FTF) group to a computer conferencing group in relational aspects. At the time of their study, online communication was accessible only through typed, written messages. Despite these messages not being received immediately by the intended recipient and the somewhat formal nature of the typed messages, they found that the relational differences between the two groups were eradicated over time. Although the slower rate of information exchange may mean it takes people who are interacting online longer to build rapport than in FTF groups, Walther and Burgoon concluded that 
relationships are affected by the participants in the groups, not by the modality of the communication. Ultimately, they found when compared to FTF groups, participants in CMC groups "do develop and evolve in relationally positive directions" (Walther \& Burgoon, p. 76). This was corroborated by Herring (2011), who noted that people who use CMC experience it similarly to spoken conversations.

Since that early study, $\mathrm{CMC}$ has become a vital part of how we communicate with others. Unlike when CMC first emerged, people now have multiple CMC modalities to utilize, such as FTF (such as Skype), e-mails, texts, and social networking sites, (Rupel \& Burke, 2014), with even more different devices in which to employ these methods, such as home computers, laptops, mobile phones, and tablets (Chan, 2015). People utilize CMC for a variety of purposes, such as meeting others, maintaining relationships, networking to find or advance employment opportunities, or connecting with others to share interests and experiences (Baker, Bricout, Moon, Coughlan, \& Pater, 2012; Orchard, Fullwood, Galbraith, \& Morris, 2014). With the many different types of devices available to people, it is possible to be connected to others virtually all the time. This type of constant connectedness can have different effects on people throughout the course of their lives (Chan, 2015).

Chan (2015) noted that use of the Internet to communicate could enhance the quality of life of an individual by allowing them to be more engaged with their community and to develop and maintain relationships, but for others increased loneliness may be the result of having to balance both an online and FTF network of relationships. Various tools are available for people to connect with others, many of them multi-modal. The term multi-modal indicates that a device can connect with others in more than one way (i.e. speaking on a phone or sending a text message). These devices, such as mobile phones, guarantee that people can interact with others 
at any given time. Although Chan noted that the idea of being 'always available' could be stressful for some, his data gathered via 514 telephone surveys with adults in Hong Kong indicated that the mobile phone was the most popular device for connecting with others. Additionally, Chan found that the older age cohorts (35-54 and 55-70+) experienced greater well-being as a result of multi-modal connectedness and strong tie-in communications. Strongtie relationships are "characterized by emotional intimacy, social support, and mutual reciprocity" (Chan, 2015, p. 7). However, for people ages 18-34, weak-tie communications impacted the relationship between multi-modal connectedness and well-being. This could be because communication with weak-ties, who are often people we think of as acquaintances, may supplant family time or opportunities to communicate with other strong-tie relationships.

Another way that people connect online is through social networking sites (SNS). These sites allow people to establish an online presence, connect with others, and use these connections to develop a wider social network (Orchard et al., 2014). Orchard, Fullwood, Galbraith, and Morris (2014) used questionnaires to determine motivations to use SNSs and found most participants engaged with two SNSs, with the range being one to six SNSs. Participants' favorite SNS was reported to be Facebook. Motivations for using SNSs were listed as procrastination, freedom of expression, conformity, information exchange, development of new connections, ritual, social maintenance, escapism, recreation, and experimentation (Orchard et al., 2014). The researchers concluded that while personality and individual differences may lead to particular motivations for SNS use, individual difference does not appear to influence frequency or fundamental usage of SNSs (Orchard et al., 2014). 


\section{ASD and Communication}

The term ASD currently encompasses a specific set of characteristics that can range from mild to severe impact. However, the term has been revised and repurposed several times in its short lifespan. Historically, there have been many different subgroups of pervasive developmental disorders (PDD) and autism spectrum disorders (ASD). Originally, autistic disorder, Rett's disorder, childhood disintegrative disorder (CDD), Asperger's disorder, and Pervasive Development Disorder, Not Otherwise Specified (PDD-NOS) were included as subgroups under the heading of PDD. However, with the advent of the Diagnostic Statistical Manual of Mental Disorders, fifth edition (DSM-5), it was determined that there were enough similarities of CDD, Asperger's disorder, and PDD-NOS to establish they "represented a continuum from mild to severe of autism" (Tsai \& Ghaziuddin, 2014, p. 324). In the DSM-5, Rett's disorder was removed from the category completely, the heading PDD was changed to ASD, and all previous subtypes are now referred to simply as ASD. This study will focus on young adults who previously were diagnosed with either Asperger's syndrome (AS) or high functioning autism (HFA) or have been currently diagnosed with ASD without an intellectual disability.

The population of people with ASD in this country continues to grow (Center for Disease Control and Prevention, 2015). According to the CDC, in 2012, 1 in 68 in children were reported to have ASD, while in the year 2000, only 1 in 150 children were given this diagnosis (CDC, 2015). It is evident that as those on the spectrum become adults, they will need supports to obtain a high quality of life. Because much of the research conducted regarding ASD refers mainly to children, learning more about adulthood is needed in the field (Hurlbutt \& Chalmers, 2002). According to Jantz (2011), "there are no evidence-based practices to address the unique 
needs of adults with AS [Asperger Syndrome]" (p. 119) and especially when it comes to their communication needs. In order to determine the best ways to help all people with ASD, it is imperative that we continue to listen to their voices to support them in achieving a high quality of life. Quality of life "is a multidimensional phenomenon composed of core domains influenced by personal characteristics and environmental factors" (Buntinx \& Shalock, 2010, p. 285), and for many people with ASD this includes forming and maintaining relationships with others.

One of the most recognizable characteristics of ASD is difficulty with social communication (Jordan \& Caldwell-Harris, 2012; Mazurek, 2013). Many individuals with ASD have difficulty initiating and maintaining friendships, particularly once they have graduated from school and prepared to transition to adulthood (Jantz, 2011). Both children and adults with ASD are aware that people have a need for social relationships, and most of them wish to have friends of their own (Adreon \& Durocher, 2007; Hillier, Fish, Cloppert, \& Beversdorf, 2007; Orsmond, Krauss, \& Seltzer, 2004; Turner-Brown, Perry, Dichter, Bodfish, \& Penn, 2008). As people with ASD may have average to above average intellect (Gutstein \& Whitney, 2002), they are often painfully aware of how their relationships with others do not mirror those of people who are not on the spectrum. Often, what prohibits them from achieving these relationship goals is a lack of social skills. Unfortunately, people with ASD often have "difficulty establishing and maintaining peer relationships, a lack of shared enjoyment of interests and accomplishments with others, and a general lack of social or emotional reciprocity" (Orsmond et al., 2004, p. 245). Friendships are created on a mutual give-and-take between two people, and though people with ASD want to have friendships with others, they do not know how to initiate contact with another person in order to make a friend (Barnhill, 2001). Research suggests that most people with ASD 
do not have any friends, and for those who do have friends, parents do much of the arranging and facilitating of the friendship (Hiller et al., 2007). Additionally, those who reported having friends found the basis of the friendship to be on a mutual interest but with no interaction beyond the shared interest. This is of particular importance because "the fewer friends a person has, the less support he or she receives from family, friends, and the work place" (Chan, 2015, p. 6).

Another reason people with ASD have difficulty making friends is that they do not always comprehend verbal and nonverbal communication (Adreon \& Durocher, 2007; Barnhill, 2001). They use language as a means to get vital information, but not as a means to communicate with others through small talk. As social norms require communicative reciprocity, people with $\mathrm{ASD}$ can be misinterpreted as rude or inappropriate because they may speak out of turn or may go on about a subject in which their conversation partner does not share an interest. This is another detriment to making and keeping friends. According to Adreon and Durocher (2007), many people do not understand why people with ASD behave or speak in certain ways, leading them to avoid contact with them. Additionally, Adreon and Durocher found that people with ASD lack the ability to have a give-and-take or reciprocal conversation with others. These types of communication misunderstandings may lead some people to feel they can tease, ridicule, or even take advantage of the person with ASD.

A lack of social competency is possibly the biggest challenge facing those with ASD. As defined by Gutstein and Whitney (2002), "social competence refers to the skills and strategies that allow individuals to have meaningful friendships; forge close, emotion-based relationships; productively collaborate with groups, teams, and work partners; manage public social settings; and participate in family functioning" (p. 161). In addition to a lack of social competence, many people with ASD may also ask questions that are not appropriate or make others uncomfortable 
with their actions or speech (Barnhill, 2001). Although there are some strategies people with ASD can rely on to ease difficulties with social communication, challenges for many persist during FTF communications.

CMC provides a unique opportunity for individuals with ASD to find others to communicate with on their own terms. "CMC is less personal or socioemotional than is face-toface (FTF) communication" (Walther \& Burgoon, 1992, p. 51), which may provide feelings of relief for those who are ill-equipped to deal with emotionally charged FTF conversations. For people with ASD who may have anxiety in social situations or difficulty reading FTF social cues, the Internet may allow them to communicate in a way that feels controlled and safe. Communicating online also provides time for people to hone their responses or answers to questions into something that may be "stereotypically desirable" (Walther \& Burgoon, 1992, p. 79), which may also relieve social anxiety for a person with ASD.

\section{Statement of the Problem}

It is important to focus on helping people with ASD feel less isolated in our society. People with ASD report a sense of loneliness and isolation throughout their lives (Muller, Schuler, and Yates, 2008). The advent of the Internet has connected people globally, enabling us to communicate with virtually anyone at any time (Sum et al., 2008) and allowing those with special interests to connect with people who share those interests no matter where they are physically located. Many people with ASD wish to have the same types of lives as their typically developing peers; they are acutely aware of the fact that, as they get older, the milestones people experience (e.g., moving out of their parents' house, managing a career, maintaining relationships, and having children) are more difficult for them to achieve than their typically developing peers (Jennes-Coussens Magill-Evans, \& Koning, 2006). The Internet is a 
relatively new method of communication but one that has forever changed the way people connect (Herring, 2011). Studies have been conducted to investigate how we utilize this powerful tool to change our lives (Brownlow \& O’Dell, 2006; Shpigelman \& Gill, 2014; Watabe \& Suzuki, 2015).

A plethora of studies documenting the social communication challenges people with ASD face on a regular basis have been conducted (Jordan \& Caldwell-Harris, 2012; Muller et al., 2008; Turner-Brown et al., 2008). However, there are fewer studies available that investigate how people with ASD use the Internet to communicate and the effects the Internet may have on their lives. Through an online questionnaire, Mazurek (2013) found people with ASD who do and do not use social networking sites (SNS) to communicate reported no difference in their levels of loneliness. Brownlow and O'Dell (2006) found through an analysis of online discussions amongst people with ASD that they use the Internet to connect with others like themselves and to empower one another. Benford (2008) conducted a mixed methods study "to explore how people with HFA or AS experience the Internet as a communication medium" (Benford, 2008, p. 274). Benford's work included a survey administered to 138 adults (minimum age 16) with high-functioning autism and Asperger's disorder and follow up interviews with 23 participants to further clarify her quantitative survey results. Benford utilized an online survey for those who used computers and a paper survey for those who did not to compare relationships between these groups. Her results indicate that many of her participants saw a benefit to using the Internet (particularly email) to communicate with others. Reasons for this included being able to better express themselves, feelings of greater control over communication, and the anonymity of CMC (Benford, 2008). They also reported they enjoyed 
being able to find others who have had similar experiences to themselves by using CMC (Benford, 2008).

Other studies have been conducted to find how people with ASD compare to people who are neurotypical in their use of CMC. Gillespie-Lynch, Kapp, Shane-Simpson, Smith, and Hutman (2014) used a variation of Benford's survey and "compared the perceived benefits and preferred functions of computer-mediated communication" (p. 456). This survey was administered to people of all ages (8-84), both on and off the spectrum. Survey results indicate people with ASD were "less likely to report that the Internet does not help them communicate" (Gillespie-Lynch, Kapp, Shane-Simpson, Smith and Hutman, 2014, p. 460) than those without ASD. Additionally, they found people with ASD perceived many benefits to communicating online, such as "increased time to think and practice interacting" (Gillespie-Lynch et al. 2014, p. 461), opportunities for self-expression, and opportunities to meet new people with similar interests or experiences. Additionally, people with ASD reported they found enjoyment in sharing experiences, writing blogs, and participating in discussion groups more so than those without ASD (Gillespie-Lynch et al., 2014). However, this same study also revealed that people with ASD found less enjoyment in using the Internet to keep in touch with family and friends and in accessing social networking sites compared to those without ASD (Gillespie-Lynch et al., 2014).

Another comparison study between people on the spectrum and those who are not was conducted by van der Aa, Pollman, Plaat, and Jan van der Gaag (2016). Their online survey was administered in Dutch to a group of people with HFA and a control group in 2010. The survey was open to adults of all ages (median age for both groups was 40) and consisted of questions designed to assess how much time was spent using the Internet and CMC. Two open-ended 
questions allowed participants to name the advantages and disadvantages they perceived of CMC. Participants were also asked to complete both a well-being scale and the Autism Spectrum Quotient (AQ). Results indicate that people with ASD tend to spend more time on the Internet and engaging in $\mathrm{CMC}$, to find more new friends or acquaintances online, and value CMC more than those without ASD (van der Aa, Pollman, Plaat, \& Jan van der Gaag, 2016).

The current data available indicate a contradiction in the way people with ASD seem to prefer using the Internet, whether it be to journal, blog, or share information about a hobby rather than connect with people over social networking sites (Gillespie-Lynch, et al., 2014; Shpigelman \& Gill, 2014), leading to a need for further study of CMC use by this population. Additionally, there is some evidence to suggest that because of the reduction of communication challenges when using the Internet, people with ASD can use this mode of communication to become better self-advocates (Brownlow \& O'Dell, 2006). Much of the available data have been collected through online surveys completed by individuals with and without ASD. Other data have been gathered through observations and analysis of information generated in Internet chatrooms.

The aforementioned studies have many similarities, both to one another and to this study. Due to the amount of time passed since Benford's dissertation in 2008, the data generated by this study is already out of date because of the significant changes in CMC in the past several years. Gillespie-Lynch et al. in 2014 explored the topic of perceived benefits to those on the spectrum against a control group in a specifically quantitative study. The most recent research in this area completed by van der Aa et al. in 2016 included participants of all ages, with a median age of 40 . Despite the similarities of some of these studies, gaps remain. This study is unique in that it focuses only on those with ASD, and on a specific age range to determine how young adults who have been exposed to technology for their entire lives perceive benefits and challenges of using 
CMC. To bridge the gap in research, this study will extend the existing research by obtaining both quantitative and qualitative information from those on the spectrum, with a specific focus on young adults ages 18-30.

A limited amount of in-depth qualitative data regarding the perceived benefits and challenges of different types of social media as seen specifically by young adults with ASD exist. This group is a niche group in terms of technology because they are the first generation who have had exposure to computers and technology for the majority of their lives. CMC is thought to have started in people's homes in the late 1980s and early 1990s (Herring, 2011), meaning this age group has also likely been aware of the Internet throughout almost their entire lives. Although studies specific to SNSs have been completed with other populations, it has been determined that use of SNSs varies based on age, gender, and personality (Orchard et al., 2014), while some with ASD prefer different types of CMC altogether (Gillespie-Lynch, et al., 2014). This current study has broadened our understanding of nuances in how young adults with ASD use and perceive their use of online communication through CMC. Overall, the purpose of this study was to explore the benefits and challenges of using CMC for communication among young adults with ASD, and additional supports they made need to access CMC.

\section{Research Questions}

- What do young adults with ASD perceive as benefits of online communication tools?

- What do young adults with ASD perceive as challenges to using online communication tools? 
- What supports do young adults with ASD report needing to use computer mediated communication to meet their personal needs (i.e. self-advocacy, socialization, community participation, connect with family, friends, acquaintances, dating/finding a significant other)?

\section{Definition of Terms}

Autism spectrum disorder. The definition of ASD has been revised many times since its original inception in the DSM III in 1980 (Tsai \& Ghaziuddin, 2014). Currently, there are five components to the diagnostic criteria of ASD according to the DSM-5. The criteria are

- deficits in social communication and social interaction across multiple contexts;

- restricted or repetitive behaviors, interests, or activities;

- development of symptoms early in life;

- symptoms cause significant impairment in social, occupational, or other facets of functioning; and

- $\quad$ symptoms are not better explained by intellectual disability.

Although there is no longer separate criteria to distinguish different "types" of ASD, such as high-functioning autism (HFA) or Asperger's syndrome (AS), for the purposes of this study, people who had previous diagnoses of either were eligible to partcipate, or anyone with a diagnosis of ASD without an accompanying intellectual disability.

Young adult. This study will focus on young adults; young adulthood can be an ambiguous term. For the purposes of this study, young adulthood will be considered ages 18-30. Graduation from high school was not a factor in defining adulthood in this study.

Social networking sites. These are defined as "web-based services that allow individuals to (1) construct a public or semi-public profile within a bounded system, (2) articulate a list of 
other users with whom they share a connection, and (3) view and traverse their list of connections and those made by others within the system" (boyd \& Ellison, 2008, p. 211).

Computer mediated communication. CMC is known as "a wide range of technologies that facilitate both human communication and the interactive sharing of information through computer networks, including e-mail, discussion groups, newsgroups, chat, instant messages, and Web pages" (Barnes, 2003, p. 4).

\section{Chapter Summary}

The recent advent of the Internet and online communication has changed the way people communicate with one another. Using email, SNSs, and other types of technology have connected people globally. People with ASD have difficulties in communicating, socializing, and often experience feelings of loneliness. Recent studies indicate that people with ASD who utilize the Internet to communicate may see benefits to alleviating the FTF component of communication. There is limited research in this area, therefore the aim of this mixed methods study was to collect data via a closed and open ended survey to determine the benefits and challenges of using CMC for young adults with ASD. Additionally, this study sought to determine what additional supports young adults need to better access CMC. 


\section{CHAPTER II: REVIEW OF RELATED LITERATURE}

In Chapter I, the social and communication characteristics of individuals with ASD and the potential of CMC as a method to mitigate some of these challenges were presented. This chapter presents a broader picture of the literature related to ASD and social communication difficulties, strategies to overcome social and communication challenges for those with ASD, the history of $\mathrm{CMC}$, and benefits and risks to utilizing $\mathrm{CMC}$.

\section{ASD and Social Communication Difficulties}

Autism spectrum disorder (ASD) is "characterized by abnormalities in social communication, social interaction, and repetitive behaviors" (Jordan \& Caldwell-Harris, 2012, p. 391). Historically, people with ASD experience difficulties with many aspects of social communication, which can impair their ability to make friends and maintain employment and can lead to a poorer quality of life than their typically developing peers (Jordan \& CaldwellHarris, 2012; Mazurek, 2013; Turner-Brown et al., 2008; White, Scarpa, Connor, Maddox, \& Bonete, 2014). People with ASD experience challenges with many aspects of communication, including "participating in impromptu and/or unstructured dialogue requiring improvised responses, understanding implicit as well as explicit meanings of messages, drawing social and emotional inferences, and interpreting and using gesture and tone of voice" (Muller et al., 2008, p. 179). These deficits in communication may lead to difficulties with social functioning, which includes interacting with others and developing positive social relationships, despite a desire to have and maintain friendships (Turner-Brown et al., 2008). While people with ASD may have friends, "their relationships are less close, less empathic, less supportive and less important to the individual compared to people without ASD” (van Asselt-Goverts, Embregts, Hendriks, 
Wegman, \& Teunisse, 2015, p. 1192) and feelings of loneliness and isolation are reported by both children and adults with ASD (Muller et al., 2008; van Asselt-Goverts et al., 2015).

In addition to a desire for friendship, many people with ASD want to have intimate, sexual relationships. In a study by Hellemans, Colson, Verbraeken, Vermeiren, and Deboutte (2007), $96 \%$ of parents or caregivers surveyed indicated that their sons had an interest in sexuality, and $42 \%$ spoke of a desire for a relationship for their son. Muller et al. (2008) also found that people with ASD lamented that even when intimate or romantic relationships were developed, it was difficult to sustain them. Lack of social skills make it very difficult for people with ASD to pursue a romantic relationship, with some specific concerns being a misinterpretation by others about intent, harassment issues, and unwanted pregnancy or disease (Wolfe, Condo, \& Hardaway, 2009). Additionally, people with ASD may not understand appropriate times to ask questions of a sexual nature, or who to ask.

Deficits in social communication skills persist into adulthood and can take on a more significant role as an individual ages out of the structure and familiarity of school and begins the transition to employment, community life, and independent living (Kandalaft, Didehbani, Krawczyk, Allen, \& Chapman, 2013; Mazurek \& Wenstrup, 2012; Turner-Brown et al., 2008; van Asselt-Goverts et al., 2015; Whitehouse, Watt, Line, \& Bishop, 2009). Some individuals with ASD have reported that they believe their difficulties with social skills combined with others' lack of understanding about autism has led to an inability to find employment (Griffith, Totsika, Nash, \& Hastings, 2011). In addition to maintaining employment, positive social interactions are also associated with good mental health and can lead to many benefits for an individual socially, financially, and emotionally (Sum et al., 2008). 
Social competence is also necessary for people to live on their own, or with minimal assistance. Hendricks and Wehman (2009) found that people with ASD benefited from living away from home, and many who resided in the family home found themselves socially isolated. Research indicates the vast majority of people with ASD will likely remain living at home and continue to be dependent on parents and caregivers (Gutstein \& Whitney, 2002; VanBergeijk, Klin, \& Volkmar, 2008). Research has also shown that people with ASD prefer the thought of support rather than actually receiving support. When people with ASD received help or support, this was not as meaningful to them as the idea of knowing that support was available. The idea of perceived support, the knowledge that help is available if needed, increased the quality of life for those with ASD (Renty \& Roeyers, 2006). However, it is difficult to ask for support of others without having the appropriate channels or skills necessary for functional or social communication.

Despite having difficulties with social communication, many people with high functioning autism (HFA) constantly work to mitigate some of these challenges (Jordan \& Caldwell-Harris, 2012). The true challenge for people with ASD is how to find and use effective interventions to develop the communication and social skills needed to reach their personal goals. One problem that researchers have found in teaching independent social skills to students with ASD was their inability to transition skills taught out of context (Gutstein \& Whitney, 2002; Hume, Loftin, \& Lantz, 2009). Possibly due to not dealing well with change, a person with ASD often cannot relate a past experience to something happening in the present. Hume, Loftin, and Lantz (2009) found that using self-monitoring skills, video modeling, and individual work systems may help increase independence of those with ASD. Likewise, Gutstein \& Whitney (2002) found that it is difficult for people with ASD to understand different perspectives other 
than their own. According to the researchers, teaching perspectives and experience sharing with others needs to happen in authentic, real-life situations. These experiences should highlight the joy of interacting with others, beginning with adults who act as guides, and then with same-aged peers. When skills and experiences happen out of context, the person with ASD is not likely to carry that experience into the future and may become dependent on others to tell them how to behave and act.

\section{Interventions}

Interventions to address deficits in communication and social skills for both children and adults with ASD have been examined. Although some interventions are effective during the treatment process or within a controlled group setting, the effectiveness does not always carryover to real-life social situations (Fletcher-Watson, Leekam, \& Findlay, 2013; Howlin \& Yates, 1999; White et al., 2014). Likewise, Turner-Brown, Perry, Dichter, Bodfish, and Penn (2008) found that while individuals on the spectrum could identify a missed social cue while watching a video, they may not recognize the same social cue in their environment when it involves them personally. Fletcher-Watson, Leekam, \& Findlay (2013) found no significant differences in how people with HFA described a series of images depicting different social scenarios compared to the descriptions of neurotypical peers. However, they also noted the possibility "that even accurate social statements by individuals with ASD do not necessarily translate into accurate social behavior in the real world" (Fletcher-Watson et al., 2013, p. 228). The researchers concluded that the desire to connect with others and develop friendships exists within those on the spectrum, and that the challenge going forward is to help "develop the social skills to match their social motivations" (Fletcher-Watson et al., 2013, p. 228). One way people with ASD sometimes work on these types of skills is through support groups. 
Support groups. Generally speaking, self-help groups have been utilized by "people with mutual needs to exert control over circumstances that affect their lives" (Braithwaite, Waldron, \& Finn, 1999, p. 125). There are many reported benefits to participation in such groups, such as sharing information, gaining new perspectives, discussing subjects generally off limits, experiencing a sense of camaraderie, problem solving, developing a sense of hope, and increasing social networks (Braithwaite et al., 1999). Support groups can provide those with ASD an opportunity to work on developing communication skills and a place where they can meet others like themselves. According to Jantz (2011), adults with ASD have sought out support groups as a way to work on social skills, have social interactions, get information and advice, have structure in their day, or follow the recommendation of a loved one or professional. Additionally, Sperry and Mesibov (2005) found that when people with ASD were explicitly taught social skills in a literal context, they were able to draw on those experiences as a resource.

However, participants also noted fears about joining support groups, such as possibly offending another group member, being judged or forced to participate, not feeling safe, or not finding the group to be helpful. Although results of the study revealed no association between how long a person spent in a group and scores on a loneliness rating scale, participants had a desire to learn from and share with their peers with ASD and to socially interact with others (Jantz, 2011). Participants also noted that they wished the support groups they joined had a more social focus, indicating "it may mean that these adults are using the group as a replacement for natural social interaction instead of as a supplement to other social interactions" (Jantz, 2011, p. 126).

Groups can sometimes serve a dual purpose of providing both social interactions and explicit instruction. An example is Aspirations, a group that allows young adults with ASD to 
have a safe place to ask questions and voice their concerns about life (Hillier et al., 2007) while also working on specific social skills. In addition to the support groups, some organizations organize an informal pre-meeting at a bar-like setting to give participants a chance to interact with each other prior to the treatment. People with ASD reported enjoying getting to know others like themselves, giving them a sense of not being isolated or alone (MacLeod \& Johnston, 2007).

Although some groups are formed by researchers to study an intervention, sometimes the greater benefit may be the social support and comradery that the groups provide (Jantz, 2011; Turner-Brown et al., 2008). Social support, which can be verbal or nonverbal, is an important facet in establishing a high quality of life (Braithwaite et al., 1999). Turner-Brown et al. (2008) utilized Social Cognition and Interaction Training to help people with ASD learn how to recognize social cues and how to distinguish socially relevant facts while also utilizing video examples of social situations. Although the results indicated that the intervention did not yield significant changes in social skills for participants, the participants self-reported that they enjoyed the group and found it useful, with some responding they liked the "opportunity to meet other adults with HFA" (Turner-Brown et al., 2008, p. 1781). Howlin and Yates (1999) found their social support group focused on understanding of social difficulties, dealing with them, improving conversational skills and working towards greater independence to be somewhat effective in helping adults with ASD by utilizing role play, team activities, structured games, and feedback. Overall, nine of the ten participants reported they felt that they had made improvements in their ability to communicate and get along with others. Further, pre and post video recordings indicated an increase in social communication. Despite these positives, Howlin and Yates found that once the participants were outside the group, it was difficult for them to 
apply their newly learned social skills in other settings. However, all participants agreed "that the group had helped by offering the opportunity to meet and listen to individuals with problems similar to their own" (Howlin \& Yates, 1999, p. 302).

People with ASD are typically aware of their social deficits, and many work to reduce these challenges by participating in special interest groups, particularly ASD groups to meet other people who face similar challenges to themselves (Muller et al., 2008). Also, the use of structured social activities, such as church or classes in areas of interest, provides opportunities for socializing, especially when a more socially capable peer takes the lead with the conversation or activity (Muller et al., 2008). Having a positive social interaction can be powerful, especially as it may motivate an individual to seek out more opportunities for interaction, leading to both improved social skills and deeper connections with others (Koegel, 2007). These types of connections can be invaluable to an individual with ASD.

Although dependency on others is not the ideal situation for people with ASD, the positive aspects of a having a strong support system cannot be overlooked. Hurlbutt and Chalmers (2002) found that a strong support system helps to raise the self-esteem of individuals with ASD; mothers in particular were found to be the greatest support for a person with ASD. Sperry and Mesibov (2005) found that having typically developing peers and friends was also a strong support for those with ASD, because they could explain things patiently and literally, giving the person with ASD time to learn social nuances. 


\section{Social Capital}

Difficulties with socializing and interacting with others is part of the everyday norm for people with ASD (Mazurek, 2013). However, there is much to be gained by working on developing these skills. Research shows that people with stronger relationships tend to be happier (Chan, 2015) and have more opportunities to prosper from these relationships (Sum, et al., 2008). One way to discuss how people interact with one another is through the lens of social capital. According to Brandtzaeg (2012), the term 'social capital' has "no single generally accepted definition or operationalization" (p. 468). However, in his study he combines the theories of others and uses the term to focus on individual social capital, which is "understood as the number of connections within and between the different social networks individuals participate in, and how often individuals are engaging in these connections" (Brandtzaeg, 2012, p. 468).

Sum, Mathews, Pourghasem, and Hughes (2008) also noted that social capital is a theory with many definitions, but generalize the concept as "the social relationships between people that enable productive outcomes" (p. 203) and find uniformity in the idea that "social capital is derived from relations with others in a social structure" (p. 204). The study of the effect the Internet can have on the social capital of others is one of increasing interest for researchers (Sum et al., 2008). As the Internet shrinks the world around us and allows people to be a click away from almost anyone, people who were previously isolated now have the opportunity to connect with others at a moment's notice, thereby possibly improving their social capital (Sum et al., 2008). This is especially important for those with disabilities, as they typically have limitations in their ability to connect with others (Shpigelman \& Gill, 2014). 
Increased social capital can be derived from participation in self-help groups. Support and self-help groups have been established for many different types of reasons since the 1970s (Cheung, Mok, \& Cheung, 2005). As people participate in the group and form relationships with people who have shared experiences, they develop social capital. The social capital, which is driven by self-empowerment gained from participating in the group, increases the benefits they gain from being a part of the group (Cheung et al., 2005). If this social capital and increase in personal empowerment can be achieved through FTF support groups, it may be possible that the same benefits can be attained through CMC.

\section{Internet Use and Social Capital}

Socializing using CMC is a different experience than communicating FTF, but many of the patterns remain the same. Due to the easy accessibility of online networks, "many everyday life activities... are replicated in online, virtual environments" (Baker, Bricout, Moon, Coughlan, $\&$ Pater, 2013, p. 23). The biggest difference in meeting someone and cultivating a friendship or romantic relationship online is the absence of the physical presentation. People have an opportunity to determine how they want to present their persona by creating carefully and well thought-out written messages (Barnes, 2003). Another difference in this type of communication is the amount of time that people must spend writing their messages, versus in an instantaneous FTF encounter. There is also the absence of body language and nonverbal cues, which can be less threatening for some (Mazurek, 2013). However, what remains the same is that both types of relationships are built on a shared expectation of reciprocity in interactions (Barnes, 2003). People who are using CMC to communicate and socialize with others want to feel as though the amount of effort they are putting into their relationships is worth what they are getting in return; this is known as social exchange (Barnes, 2003). 
People who are considered to be in a privileged group tend to have greater social capital, while those in marginalized groups (such as people with disabilities) have lower social capital (Sum et al., 2008). In a study completed with senior citizens, Sum et al. (2008) found that for people with little social capital, using the Internet could increase social capital by a small amount. The researchers also noted that the ways in which people use the Internet are as important as the amount of time spent online. Additionally, Chan (2015) noted that "over 2 decades of research has generally demonstrated a positive relationship between Internet use and a variety of well-being indicators across a variety of populations" (p. 5). Chan's study, which focused on adults ages 18-70 in Hong Kong, found that connectedness and well-being varies according to age and weak-tie relationships (Chan, 2015). Herring (2011) also noted people who spend more time socializing using $\mathrm{CMC}$ tend to have more social interactions offline. This combined knowledge of the possible effect of Internet use on social capital can and should be capitalized on to support people with ASD.

Many recent studies have focused on how people use the Internet or social networking sites (SNS) and the effect on their social capital or other factors related to their well-being (Brandtzaeg, 2012; Chan, 2015; Gilliespie-Lynch, et al., 2014; Mazurek, 2013; Ong et al., 2011; Orchard et al., 2014; Sum, et al., 2008). There are different factors that can be used to predict if utilizing the Internet to communicate online will help increase social capital or overall social well-being. One factor to consider is the amount of friends a person utilizing the Internet has offline. Ong, Chang, and Wang (2011) noted that data indicate people who already had strong relationships offline found a deeper, stronger connection with those same people online while those with lower quality friendships did not. This was corroborated in their study, in which they collected data via questionnaires completed by university students that concluded "social 
loneliness is associated not with the time spent online, but with the quality of social relationships" (Ong et al., 2011, p. 39). This is not surprising, as most of the 'friends' people have online via SNS are not really friends in real life but rather a collection of acquaintances or connections people have via work or other networks, resulting in weak-tie relationships (boyd \& Ellison, 2008). Typically, when people join SNS, they want to connect with their existing friends and expand their networks through establishing ties with acquaintances, not meet new people (boyd \& Ellison, 2008). Additionally, Brandtzaeg (2012) found through a longitudinal study comparing the social capital of those who use SNS and those who do not that "sns users are actually more likely to socially interact face-to-face and report more social capital than nonusers" (p. 483).

Groups can also form social capital. A study of women in an online support group centered on pregnancy, mothering, and fertility (Ley, 2007) revealed that commitment to the group played a large part in the success of the organization. Ley notes that "the more social capital a group possesses, the stronger and healthier the group is" (2007, p. 1390) and that research has shown "that social capital in online support groups provides emotional and psychological benefits to participants" (Ley, 2007, p. 1390). In this particular study, people felt connected to the other participants in their group, confided with them regarding confidential matters, and even met one another offline, resulting in stronger relationships. People who participated in this group reported feeling informed, cared about by others, and having a sense of belonging (Ley, 2007).

\section{Computer Mediated Communication}

Although for many of us it is difficult to imagine a time without it, online communication is in its infancy. The first email was sent in 1972; people were able to chat online from their 
homes beginning in the late 1980s (Herring, 2011). CMC, most simply defined as "a form of electronic written communications" (Barnes, 2003, p. 4), has forever changed the way that people are able to access and relate to others. There are many different types of CMC. The earliest forms included electronic mailing lists, bulletin board discussion systems, multi-user domains (MUDs) and Internet Relay Chats (large, text-based multi-participant chat systems) (Herring, 2011). In addition to those listed above, CMC now encompasses even more genres, including e-mails, real time online chatting, online games, and web pages with built in discussions and chatting options. People use CMC for a variety of reasons, most notably for “interpersonal communication, information seeking, and entertainment" (Barnes, 2003, p. 137). Being able to share and keep in touch with others has been a primary motivator for those using the Internet since almost its inception (Barnes, 2003).

Most types of CMC can be classified as either synchronous or asynchronous. Synchronous communication happens live, or in real time, while asynchronous communication means that people can read messages at different points in time (Barnes, 2003). Some common types of synchronous communication are instant messages, text messages, and online chat rooms, while common examples of asynchronous communication are e-mail, forums, discussion lists, and newsgroups (Barnes, 2003). In synchronous communication, people are receiving information almost as fast as an individual can type. When communicating in this manner, regular turn taking as would happen in spoken communication often gets disrupted because of overlapping exchanges and occasional delays in feedback or response from a communication partner (Herring, 2011). In asynchronous exchanges, people have more time to craft and edit their responses before sending them to be read by others (Herring, 2011). Asynchronous exchanges, such as blogs, are considered less conversational than other types of CMC because 
they are driven mainly by the author with others able to respond if they so desire. Despite the obvious differences in the genres of CMC and between CMC and FTF communication, many people describe their CMC similar to how they describe their FTF interactions, which indicates that CMC "fulfills many of the same social functions as spoken conversation" (Herring, 2011, p. 4).

\section{CMC Genres}

There are a variety of ways to connect with people online, and a variety of reasons why people choose to do so, such as "information sharing, engaging in online debate, asking and answering questions, flirting, social contact, playing games, and advocating political positions" (Barnes, 2003, p. 137). These different genres are represented throughout the Internet. Some websites also overlap genres, meaning they may offer functionality typical of one type of genre while also offering components of another. Though this list of examples is not comprehensive, some discussion/informational groups, SNSs, and online support groups will be discussed for the purposes of this study.

Discussion/informational groups. One type of CMC genre is the discussion group. Wrong Planet (wrongplanet.net) is a group that seeks to connect and inform people with ASD. This web community provides a space where people can discuss autism news and have an outlet to share experiences. People can connect on this website based not only on a shared experience of having ASD, but also on a variety of different interests. Users can post replies to previous threads or start new topics. There are norms and rules posted on the site to ensure that people who participate can understand the expectations of this particular online community. In addition to being a discussion group, Wrong Planet also provides articles and resources regarding autism, a blogging feature, and an opportunity to live-chat with others. 
Social networking sites. There are hundreds of different SNSs currently available to those who want to share information with others. There are defining characteristics of what constitutes a SNS, such as allowing people to connect with others, being able to indicate affiliations to individuals or groups, and allowing others to publically display their social connections (boyd \& Ellison, 2008). Most SNS have features allowing people to create a profile for others to view with varying degrees of access, an ability to publically display personal connections with others, and an option to label people as 'friends' (boyd \& Ellison, 2008). People use SNS for a variety of purposes. Some SNSs were created to allow people to maintain current social networks, while others "help strangers connect based on shared interests, political views, or activities" (boyd \& Ellison, 2008, p. 210). There are SNSs that are designed to include all people, while others try to serve a niche group or people with shared interests. SNSs can serve many different functions for people, however they often attract homogenous groups (boyd \& Ellison, 2008). No matter the reason for using one, research indicate that SNSs are gaining in popularity worldwide (boyd \& Ellison, 2008), with the amount of people using these sites "fast approaching one billion in number" (Baker, et al., 2013, p. 32).

SNSs as we know them began in the late 1990s. The first site was SixDegrees.com and allowed for people to "create profiles, list their Friends and, beginning in 1998, surf the friends list" (boyd \& Ellison, 2008, p. 214). Although other websites may have boasted some of these features prior to the launch of SixDegrees, they were the first to combine them all. Although SixDegrees is no longer in business, it is a blueprint for many of the online tools we use today. LiveJournal, a SNS with a blogging component, was created in 1999 and allows users to manage privacy and accept Friends who are then able to follow their online journals (boyd \& Ellison, 
2008). LinkedIn was developed in 2003 as a business-related SNS and is "the largest platform dedicated solely to professional networking" (Baker, et al., 2013, p. 23).

Some SNSs start out by appealing to a niche group and then branch out to include everyone. Facebook is one such site. Initially designed for use only by Harvard students, Facebook was first expanded to all university students, then to high school students, then corporate networks, and finally everyone had access (boyd \& Ellison, 2008). There are hundreds of millions of people with Facebook accounts, and Facebook is "generally associated with community and group interaction" (Baker, et al., 2013, p. 23).

Although they may serve different purposes or populations, SNSs are primarily organized around people, not special interests (boyd \& Ellison, 2008). However, SNSs are often like communities, because they allow groups of people to connect on a variety of issues that are important to them. Being a part of a social network allows people the same advantages that being a part of a community can offer.

Online support groups. Online support groups, which began in the 1990s (Barak, Boniel-Nissim, \& Suler, 2008), are common and have been established for a variety of reasons. Many were created to discuss different issues centered on family, life, or health issues (Ley, 2007). It is estimated that there may be hundreds of thousands of online support groups presented through a myriad of Internet channels - chat groups, forums, or email lists (Barak et al., 2008). People utilize these groups to get information and support, communicate with others, and form social ties (Ley, 2007). People who participate in online support groups do so to "transmit and obtain information, provide and receive emotional support, socialize and form interpersonal relationships, and experience comradeship with others sharing similar distress" (Barak et al., 2008, p. 1868). Despite the many types of online support groups (or perhaps 
because of the many types), finding one best-suited to an individual can be difficult. Observing an online group for a period of time and evaluating a response to a user's post are helpful in determining if the group is right for the individual (Barak et al., 2008).

Batenburg and Das (2015) found that individuals with cancer who participated in an online support group experienced an increase in emotional well-being over time. The researchers also noted that approximately half of people in health support online communities do not post; they only read the posts of others. While those who read may experience psychological benefits, those who post may enjoy greater benefits because they are more connected and engaged with the online community (Batenburg \& Das, 2015). Likewise, Green-Hamann and Sherblom (2014) noted that CMC allows people a venue to "vent frustrations reduce personal stress, and generally meet their informational, emotional, belonging, self-esteem, and personal identify needs" (p. 1131).

\section{Benefits of CMC}

There are many perceived benefits of using CMC. Many people who connect online describe their experiences the way they describe their FTF interactions. Although there is no evidence to suggest $\mathrm{CMC}$ would supplant face to face communication, $\mathrm{CMC}$ is already a trend in the general public (Herring, 2011). One benefit to CMC is that people can write messages in almost complete anonymity, which allows them to write more expressively and openly regarding their thoughts while also maintaining a degree of privacy (Green-Hamann \& Sherblom, 2014). The feeling of being able to expose oneself more freely and openly online without inhibition is called online disinhibition effect (Barak et al., 2008). In some cases, being a part of an online community can increase an individual's social capital or feelings of empowerment, allowing them to fulfill their desire to be an active participant in a community (Baker et al., 2013; Barak et 
al., 2008). In addition to helping to strengthen existing social relationships and increase social capital, interacting with others online can be a great support for those who are in need of sharing experiences with others in similar situations (Batenburg \& Das, 2015; Green-Hamann \& Sherblom, 2014).

\section{Risks of CMC}

Despite the current trend in utilizing CMC and accessing SNSs, there are some potential drawbacks to this type of communication. To start, well-intentioned people may give out advice that is not sound, or misinformation, leading to more harm than good (Braithwaite et al., 1999). There are practical risks, such as a possible invasion of privacy or a disconnect between a desire to maintain privacy and online behavior when connecting with others on SNS (boyd \& Ellison, 2008). The online disinhibition effect, which can be so helpful when trying to open up to a group, can lead to malicious behavior such as "rude language, harsh criticisms, anger, hatred, or even threats" (Barak et al., 2008, p. 1870). People may encounter unkind or malicious behavior via online communications. Since the Internet allows for anonymity, sometimes people feel as though they can behave in a manner they would not normally express in public or to a person's face (Braithwaite et al., 1999). Those who are either young or somewhat vulnerable could be susceptible to being 'friended' by someone who would then attempt to solicit private information (boyd \& Ellison, 2008). Some studies have indicated that communicating online can lead to increased loneliness (Brandtzaeg, 2012; Chan, 2015; Ong et al., 2011) because the amount of time needed to maintain an online presence diminishes the amount of available time to maintain face-to-face relationships (Chan, 2015). Ong et al. (2011) found that people who spent time communicating online experienced less social loneliness but greater familial loneliness, indicating a need for balance in online chatting and spending time with family. Brandtzaeg 
(2012) noted that "heavy SNS usage for males seems to amplify feelings of loneliness" (p. 483). Batenburg and Das (2015) found that when people use Facebook, they may experience feelings of negativity if they perceive their life to be inferior to that of an online friend, but may also experience feelings of positivity if they compare favorably to a friend. Research also indicates that more time spent on Facebook has led to reduced social capital and increased loneliness in users (Batenburg \& Das, 2015). Also, people who are "Friends" online, are not always actual friends offline or in the everyday sense (boyd \& Ellison, 2008). This can be confusing for some and cause social conflict for others. It's also possible people may become addicted to the online support, therefore neglecting their offline relationships, which are also important to their daily well-being.

Overall, many studies are conflicting regarding the potential benefits or negatives of using the Internet to communicate (Brandtzaeg, 2012; Ong et al., 2011). Although there is research suggesting people who are introverted do not use the Internet to socialize (Mazurek \& Wenstrup, 2012), others noted "introverted people with high levels of loneliness and low levels of self-esteem tend to establish meaningful relationships in cyberspace" (Ong et al., 2011, p. 36), while Orchard, Fullwood, Galbraith, and Morris (2014) found that introverts enjoy communicating online, but did not typically prefer SNS as much as those who are extraverts. Obviously, there are many different variables that affect the social outcomes of people who communicate online and no two groups are the same (Orchard et al., 2014). Exploring specific populations and the way they interact with $\mathrm{CMC}$ provides valuable insights into working with people to strengthen and maintain social relationships. 


\section{Online Communication and Disability}

People with disabilities can also benefit, perhaps uniquely, from CMC. Communication barriers such as location are removed because there is always someone available to communicate with via the Internet. People with disabilities can interact with others via chat rooms, online games, or other activities they may enjoy but wouldn't be comfortable doing in a face to face relationship (Barnes, 2003). Individuals who are deaf can communicate with others who don't know sign language (Barnes, 2003; Braithwaite et al., 1999). People who are unable to communicate verbally are able to compose and send messages at their own pace, while people who prefer typing to talking may also benefit from CMC (Braithwaite et al., 1999). Using the Internet to communicate has the possibility of connecting people who may otherwise experience isolation and loneliness. Socializing with others is not only enjoyable, but is an important life function that can lead to greater health benefits and reduced mental illness (Braithwaite et al., 1999; Chan, 2015); without socialization, people are susceptible to problems such as “depression, loneliness, alienation, lack of social interaction, lack of information, and lack of access to employment" (Braithwaite et al., 1999, p. 127).

\section{Online Disability Support Groups}

Additionally, online support groups are a way of providing social support to people with disabilities who may not be able to physically travel to a FTF support group, or who would struggle with verbal communication (Braithwaite et al., 1999). While online support groups often function the same way as FTF support groups, CMC allows for greater flexibility by eliminating barriers such as travel and timing. This may be particularly helpful for people with

disabilities "who may find face-to-face access especially problematic due to challenges of mobility and access" (Braithwaite et al., 1999, p. 127). The Internet allows for a greater amount 
of participants, which can increase the number of perspectives that a person who needs support can obtain (Braithwaite et al., 1999). Also, people who are not a member of a particular disability group can learn more about others and also benefit from the participants' experiences. Other benefits include a longer 'wait time' than in FTF groups. Supporters have a longer time to formulate responses to queries regarding services or care without having to give an immediate response, or may use time offline to research different types of care or services available (Braithwaite et al., 1999).

People in support networks utilize them for a variety of reasons, but the Internet allows those with disabilities to find more people like themselves to connect with than they would likely be able to find in their own communities without it. Braithwaite, Waldron, and Finn (1999) conducted a study by reading and coding messages sent by participants in a disability support network in the United States. The researchers utilized the Social Support Behavior Codes framework developed by Cutrona and Suhr, under which there are five types of support: informational, tangible, esteem, network, and emotional (Braithwaite et al., 1999). Informational support refers to offering information or advice. Tangible support offers helpful services. Emotional support refers to empathy. Network support provides a sense of camaraderie. Esteem support provides value for a person's worth as a human being (Green-Hamann \& Sherblom, 2014). They determined that the most common type of message sent by a participant was an emotional support message ( $40 \%$ of all messages), followed by informational support messages (31.7\% of messages), esteem support messages ( $18.6 \%$ of messages), network support ( $4.1 \%$ of all messages), and finally tangible support (2.7\%) (Braithwaite et al., 1999). Based on the collected data, the researchers ultimately suggest "that members of computer groups like Support 
Network actively help one another to manage some of the physical and social limitations imposed by disability" (Braithwaite et al., 1999, p. 142).

In addition to using the Internet to communicate with others like themselves, people with disabilities also utilize SNSs that are designed for all people. Facebook and LinkedIn, two popular SNSs, are used by millions of people worldwide (Baker et al., 2013). In a study that compared usage of these two sites between people with disabilities and older or 'aging' adults, it was found that Facebook and LinkedIn were both mainly used for their primary purposes: social networking and employment, respectively (Baker et al., 2013). However, it was also noted that LinkedIn had more searches in the category of health and wellness than Facebook, while Facebook had almost as many searches regarding employment as LinkedIn. These results indicate that many sites are being used both socially and professionally (Baker et al., 2013).

\section{Online Communication and ASD}

The various genres of online communication, such as online chatrooms and forums, blogging, and SNSs, can work to the advantage of people with ASD. It has been noted that using computers and the Internet are systemic and organized in such a way that it may align with the rule-following minds of those with ASD (Gillespie-Lynch et al., 2014). Communicating with people FTF can be overwhelming for people with ASD (Mazurek, 2013). However, the Internet provides opportunities to connect with people around the world, while eliminating components of FTF communication, such as maintaining eye contact, interpreting social cues, and deciphering body language. Several studies have found computer mediated communication allows many individuals with ASD to share information more effectively by reducing the challenges they encounter during face-to-face interactions (Brownlow \& O’Dell, 2006; Muller et al., 2008; Watabe \& Suzuki, 2015). Additionally, using technology can be very motivating for 
people with ASD, as they often have a desire to use computers and technology (Gillespie-Lynch et al., 2014; Kuo, Orsmond, Coster, \& Cohn, 2013; Mazurek, 2013) and many “prefer written over spoken communication" (Watabe \& Suzuki, 2015, p. 27). Communicating via the Internet may allow those with ASD to be "freed from the constraint of the coexistence of verbal and nonverbal communication" (Watabe \& Suzuki, 2015, p. 33) and reduce the anxiety they may experience during FTF interactions (Gillespie-Lynch et al., 2014). Gillespie-Lynch et al. (2014) analyzed survey data collected from people ages eight to 84 with and without ASD regarding using the Internet and found people with ASD reported benefits to using the Internet, such as ease of communicating (i.e. increased time to think before having to interact, being able to edit a response, or determining whether or not to be available), choice about who to interact with, opportunities to interact with others like themselves, and an ability to express one's true self. Since people with ASD may have difficulty with expressing themselves in face to face situations, CMC allows the individual an opportunity to formulate and present an identity based primarily on text without having to worry about body language, facial cues, or other visual information that a communication partner would be able to see during face to face contact (Barnes, 2003).

Using online technology can be a way for people on the spectrum to connect more easily with others. In a study with adult males on the spectrum, compared to both a control group of males without identified disabilities and a group of males with schizophrenia, results of a questionnaire about Internet usage revealed that people with ASD scored significantly higher than the control group in being able to "inform others of what I want to say more correctly through the Internet than face-to-face communication" (Watabe \& Suzuki, 2015, p. 31). Watabe and Suzuki (2015) also found that those with ASD preferred using a personal computer (PC) to a mobile phone to access the Internet, and that they overall communicated online with more 
strangers than the control group but less with people they knew than the control group.

Conversely, studies completed with adolescents on the spectrum have found that those who socialize online with family and friends rather than strangers and acquaintances tended to develop better social relationships and stronger connections with existing friends because of the increased social support offline (Kuo et al., 2013; Mazurek \& Wenstrup, 2012). Mazurek and Wenstrup (2012) noted that adolescents with ASD spent significantly less time per day using social media than their neurotypical peers, while Kuo, Orsmond, Coster, and Cohn (2013) found that adolescents on the spectrum who were using social media were older than those who were not using social media. Research has shown that people who are introverted or have social anxiety may not socialize on the Internet (Mazurek \& Wenstrup, 2012), yet other researchers "found that adolescents with ASD who used computers for social purpose reported more positive friendships than those who used computers for other purposes" (Kuo et al., 2013, p. 921). Mazurek (2013) also found through a questionnaire given to people with ASD that those who used SNS were more likely to have a close friend and to use SNS to deepen their relationship with that friend.

In addition to making it easier to communicate with others, communicating online has other benefits for people on the spectrum. One benefit is that it provides space online for people to find and connect with others like themselves (Brownlow \& O'Dell, 2006; Gillespie-Lynch et al., 2014). Since Internet communication removes some of the challenges of communicating FTF, people with ASD have the opportunity to share information on their own behalf and become better self-advocates (Brownlow \& O’Dell, 2006). Some have found that online social networks for those with ASD have been a space where they can fit in and share experiences (Brownlow \& O’Dell, 2006; Griffith et al., 2011). Brownlow \& O'Dell (2006) studied online 
communication in an ASD discussion group and found participants wanted to be a part of the 'autistic community'. They also noted that the "Internet can provide a tool with which to interact with other people who have AS and, in doing so, create an arena where AS is constructed in a positive light” (Brownlow \& O’Dell, 2006, p. 320). This forum for communication is significant, as many people with ASD value the experiences of others like themselves over the advice and suggestions of those who are neuro-typical (Brownlow \& O’Dell, 2006; Griffith et al., 2011). This is corroborated in a study by Griffith, Totiska, Nash, and Hasting (2011) who found through semi-structured interviews that adults with ASD believe they have many advantages over neuro-typical individuals, in addition to "more knowledge than many professionals" (Griffith et al., 2011, p. 541). Since many with ASD feel as though they are often trying to be normalized by people who are not on the spectrum (Brownlow \& O'Dell, 2006), the importance of having an online community where people with disabilities can feel safe to share and learn from others like themselves cannot be overstated.

There are a variety of websites available to those who want to connect with others who have ASD. Many individuals on the spectrum are interested in computers (Goodwin, 2008, p. 126); this interest may help people connect with groups electronically that would otherwise have a difficult time reaching out to others in person. SpectrumSingles.com is an online group that was created by people on the spectrum for others to find relationships or friendships with others who have ASD. This website utilizes information about the individual to make a match with someone who would be a compatible companion based on the individual's characteristics. As mentioned above, Wrong Planet is a website that is designed to connect people on the autism spectrum. Another helpful online resource is Self-Advocacy Online. Using this website, people with disabilities can type in their state or zip code to find a variety of self-advocacy groups in 
their area. For some people with ASD who may be more comfortable with technology than with meeting people in person, this tool can be used to view videos of people speaking about different aspects of self-advocacy.

However, some people with disabilities experience trepidation about disclosing their disability online. Shpigelman and Gill (2014) surveyed people with disabilities regarding their perceptions and use of Facebook and found that "on average, people with disabilities use Facebook for connecting with nondisabled friends and groups rather than connecting with their disabled friends and groups" (Shpigelman \& Gill, 2014, p. 615). Some participants noted that they prefer other online modalities such as Twitter or blogging platforms to discuss their disabilities because they worry about the privacy settings on Facebook. Despite this, one participant noted that using Facebook "reduces my feeling of being isolated" (Shpigelman \& Gill, 2014, p.618). Overall, the researchers determined that although people with disabilities are not likely to attempt making new friends using Facebook; there is an importance to their participation in fostering a sense of belonging to the community (Shpigelman \& Gill, 2014). Similarly, Gillespie-Lynch et al. (2014) found that people with ASD enjoyed using SNS less than those without ASD but liked using the Internet more to meet others with similar interests and experiences than those without ASD. Like participants in Shpigelman and Gill's study, respondents with ASD in the study completed by Gillespie-Lynch et al. were more likely to be drawn to blogs or discussion boards rather than SNS.

Online forums can be of particular significance to those with ASD. Using quantitative analysis of posts people with ASD made in online forums, Jordan and Caldwell-Harris (2012) found the individuals posting have a variety of special interests they enjoy discussing, and that Internet forums provide spaces to share these interests with others. Another benefit to 
participating in online forums is that the use of ASD forums may be "fulfilling a desire for social interaction online and concurrently circumventing the anxiety of real-life conversations" (Jordan \& Caldwell-Harris, 2012, p. 398). Gillespie et al. (2014) also noted that Internet groups may give people with ASD a place to practice interacting and a space to reveal more of their autistic aspects they may typically try to hide from others.

Another benefit to online communication is the ability of people to share information from home, which may make them feel more comfortable and able to honestly self-report (Jordan \& Caldwell-Harris, 2012). This is supported by Muller, Schuler, and Yates (2008) who also noted that participants in their study found communicating through the Internet or writing less stressful than speaking face to face or on the telephone. Mazurek (2013) inadvertently collected information regarding perceived benefits in his study designed to determine social media use in adults with ASD, with $13 \%$ of participants "spontaneously report[ing] specific benefits of electronic social media" (p. 1712), such as not having to make small talk or limiting emotional communication.

\section{ASD and Risks of CMC}

Use of the Internet by people with ASD offers a new way to connect while eliminating some of the typical stressors people on the spectrum typically experience while communicating in person. Mazurek and Wenstrup (2012) noted that "social media may offer promise for enhancing social interaction among individuals with ASD, given that computer technology provides a more controlled and predictable environment than face-to-face interaction" (Mazrek \& Wenstrup, 2012, p. 1260). Despite the perceived benefits, there are potential drawbacks when communicating online. People with ASD are at risk to be victims of cyberbullying or may begin to use the Internet excessively (Watabe \& Suzuki, 2015). The Internet also provides users 
anonymity, which means that there is no way to verify that people who use Internet forums and provide information about their experiences with ASD are actually on the spectrum (Brownlow \& Dell, 2006; Jordan \& Caldwell-Harris, 2012). Chat rooms are considered risky because they involve direct communication with virtual strangers (Orchard et al., 2014) which in theory can lead to someone with ASD being exploited or endangered based on information they disclose online, especially as they may misconstrue information given to them or requested of them (Shpigelman \& Gill, 2014). People with disabilities may have limited access to technology, unawareness of Internet safety or have difficulty reading, accessing, or interpreting the information on SNS (Shpigelman \& Gill, 2014).

\section{Chapter Summary}

People with ASD have difficulties with communication and social skills. These limitations include difficulty with eye contact, limited awareness of nonverbal cues, and needing extra time to prepare a response. These limitations make it difficult for people with ASD to develop and maintain relationships with others. Without these relationships, people with ASD have a limited ability to gain social capital, which deprives them of potential opportunities for happiness, wellness, and other health benefits. CMC can mitigate some of the social deficits experienced by those with ASD by allowing individuals to focus on responding only to written communication in a comfortable setting on the individual's own timetable. Previous research indicate that people with ASD benefit from the added 'wait time' and prefer written to spoken communication to get their point across. Despite some potential risks in using the Internet to communicate, it appears that this type of communication may be beneficial to those with ASD. 


\section{CHAPTER III: RESEARCH METHODS}

\section{The Study}

People all over the world are using CMC to connect with others. Social networking sites, informational groups, online support groups, and other channels for connection are available at a moment's notice. For people with ASD, CMC may be a way for them to overcome some of the social and communication barriers they encounter when trying to interact with others FTF. The purpose of this study was to explore the perceived benefits and challenges those with ASD have when using technology to communicate, and to better understand possible supports needed when accessing CMC.

\section{Design}

This study was an in-depth look at how young adults ages 18-30, regardless of high school completion, with ASD use computer-mediated communication and what they perceive as the benefits and challenges of utilizing CMC. In order to collect these data, I completed a mixed methods study via a survey with both closed and open ended questions, with an option to follow up with willing participants in semi-structured interviews. A mixed methods study, defined by Creswell (2014) as "an approach to inquiry that combines both qualitative and quantitative forms of research" (Glossary), "provides a stronger understanding of the problem or question" (Creswell, 2014, Chapter 10, para. 1) than either a quantitative or qualitative study could by itself.

Mixed methods is a relatively new research design; it originated late in the 1980 s and early 1990s (Creswell, 2014). Sometimes defined by other terms, but most commonly referred to as mixed methods, it is used to collect and connect both quantitative and qualitative data (Creswell, 2014). This method is used to mitigate the limitations of both types of research while 
capitalizing on the strengths of both to lead to a deeper understanding of the research questions (Creswell, 2014).

Both quantitative and qualitative designs were relevant to this research. First, it was important to establish whether or not young people with ASD are using CMC and their preferred methods of doing so; this was examined through a closed-ended survey, which yielded quantitative data. However, it is also worth noting which types of sites people with ASD are choosing to visit, and what other resources they may need in order to access other methods of CMC they are not currently utilizing. These data were determined to be obtained via open ended, qualitative questions. Therefore, a mixed methods approach for this study was deemed most appropriate. Additionally, through the open ended questions and semi-structured interviews I was able to determine some common themes in the perceived benefits and potential risks using these qualitative data.

I began this study via a convergent parallel mixed methods approach; I simultaneously collected both qualitative and quantitative data, but analyzed them separately (Creswell, 2014). I examined the data to determine if the quantitative data could be confirmed by the qualitative data. However, due to a lack of qualitative data collected in the original survey, follow-up interviews with selected participants meant that the design transitioned to an explanatory sequential mixed methods study (Creswell, 2014). This type of study involved collecting and analyzing quantitative data at the start of the study, then obtaining additional qualitative data from the original participants to strengthen the quantitative data.

\section{Participants}

For a study involving a survey, having a large sample is important. In order to make generalizations about the population based on the sample, many participants are needed to make 
the data useful. The population in this study was young adults with ASD. Therefore, people with a diagnosis of ASD ages 18 to 30 (regardless of high school completion) and who use the Internet for communication were considered eligible and invited to participate in the study. Since the study took place via an online survey, it is inevitable that those who completed it are Internet users of some degree. A convenience sample of participants were recruited for the study by posting invitations online using sites such as Facebook, Twitter, and through personal contacts, particularly those who work with people on the autism spectrum or with disabilities in general. Advocacy groups, such as Autism Speaks, Sibling Leadership Network, and the Autism Society of America, were contacted in an effort to reach more people with ASD. Autism Speaks posted the link to the survey on their website once IRB approval was obtained.

Surveys were distributed online in an effort to reach the highest number of possible participants. For a quantitative, survey based study, I ideally wanted a minimum of 100 participants, with at least 20-30 of respondents answering the open ended questions to support a grounded theory approach to analysis (Creswell, 2013). However, while 51 people clicked on the link to the survey and indicated they wished to continue the survey after viewing the informed consent, just under half $(\mathrm{n}=21)$ completed the questions in the survey. To obtain more data, semi-structured interviews were completed via email with three of the people who responded to the survey and gave consent to be contacted for follow up questions was necessary. Of these three people, two gave comprehensive, substantiated answers that were able to corroborate with the survey data.

Another reason the survey was distributed online was to reduce the difficulties with FTF communication that people with ASD experience. Benefits of online communication include more time to think about responses, not having to read face-to-face social skills, answering 
questions in the comfort of one's own home, and utilizing written communication in lieu of speaking (Watabe \& Suzuki, 2015). Research shows that being able to communicate in an environment of one's choice may make the participants feel relaxed and comfortable, thereby allowing participants the freedom to give honest feedback in their survey responses (Brownlow \& O’Dell, 2006).

Qualifying questions. Fifty-one people clicked on the link that led to the informed consent and survey (Appendix A). Of these 51 people, 50 (98\%) selected "yes" to continue with the study after reviewing the informed consent. The individual who selected "no" was thanked for his/her interest and exited from the survey.

Qualifying questions were asked of the 50 participants who indicated an interest in going on with the study. To continue, participants had to disclose a diagnosis of ASD, report being within the age range of 18-30, and confirm they use the Internet for communicating with others.

In order to continue with the survey, participants needed to verify they had been diagnosed on the autism spectrum. Of the 38 participants who answered this question, 33 (87\%) indicated they had been diagnosed with ASD, five (13\%) reported they had not been diagnosed with ASD, and 13 participants skipped this question. The five participants who indicated they had not been diagnosed with ASD were thanked for their interest and exited from the survey. Participants were then asked who diagnosed them with ASD. Of the 21 participants, all 21 provided an answer for this question. Results are displayed in Table 1.

The option, 'other, please specify' yielded an answer of “therapist". Interestingly, 34 participants answered this question, while the question preceding it indicated that only 33 participants were willing to disclose a diagnosis of ASD. This extra participant may fall into the 
"prefer not to answer" category on this question, or one of the participants may have been confused when answering the questions.

Table 1

ASD Diagnosis

\begin{tabular}{lcc}
\hline Made Diagnosis & $\mathrm{n}$ & Percentages \\
\hline Psychiatrist & 12 & $57 \%$ \\
Doctor & 4 & $19 \%$ \\
School Psychologist & 2 & $10 \%$ \\
Prefer not to answer & 2 & $10 \%$ \\
Other, please specify & 1 & $5 \%$ \\
Self-diagnosed & 0 & $0 \%$ \\
\hline
\end{tabular}

Participants were asked to identify their age range, and all 21 participants completed this question. Participants who responded "younger than 18 " $(\mathrm{n}=2)$ and "over 30 " $(\mathrm{n}=6)$ were thanked for their interested and exited from the survey. Results are displayed in Table 2.

Table 2

Age Range of Study Participants

\begin{tabular}{lcc}
\hline Age Range & $\mathrm{n}$ & Percentages \\
\hline $18-21$ & 1 & $5 \%$ \\
$22-24$ & 8 & $38 \%$ \\
$25-27$ & 6 & $29 \%$ \\
$28-30$ & 6 & $29 \%$ \\
\hline
\end{tabular}


The final qualifying question asked participants if they used the Internet to communicate with others. Any participants who answered this question with "no" $(n=3)$ were thanked for their interest and exited from the survey. The remaining participants were able to continue with the survey.

A total of 17 participants were exited from the survey after completing the informed consent and qualifying questions section of the survey, leaving a possible total of 34 participants to continue and answer the remaining questions. A review of individual surveys indicated a number of participants dropped out of the survey after completing the qualifying questions, and others dropped out after completing the demographic questions. Therefore, for the remainder of this analysis, $\mathrm{N}$ can be considered 21.

Participant demographics. Participants were asked a series of demographic questions in order to learn more about the make-up of the participants. Questions were asked regarding gender, ethnic background, marital status, living situation, education, and employment.

Participants were given an open-ended space to respond to the question 'what is your gender?' Of the 21 participants, only 19 provided an answer. This could be in part because participants were not comfortable disclosing this information, or perhaps did not understand. Results are displayed in Table 3.

Although the number of male participants is nearly double that of female participants, I expected it to be a much larger discrepancy, especially since according to Autism Speaks (https://www.autismspeaks.org/what-autism/facts-about-autism, 11/24/16), boys are nearly five times as likely to be diagnosed as girls with autism spectrum disorders. One participant responded female/genderqueer. According to urbandictionary.com, genderqueer is someone "who feels that his/her gender identity does not fit into the socially constructed "norms" 
associated with his/her biological sex"

(http://www.urbandictionary.com/define.php?term=genderqueer, 11/24/16). Another participant responded "two-spirit", which is a Native American term, indicating a person who embodies both math and female characteristics (http://www.willsworld.org/twospiritq-a.html).

\section{Table 3}

Participants' Gender

\begin{tabular}{lcc}
\hline Gender & $\mathrm{n}$ & Percentages \\
\hline Male & 11 & $58 \%$ \\
Female & 6 & $32 \%$ \\
Female/genderqueer & 1 & $5 \%$ \\
Two-Spirit & 1 & $5 \%$ \\
\hline
\end{tabular}

Participants were asked to identify their ethnic background, with an option to choose more than one answer. Participants selected between one and two answers for this question. Results are displayed in Table 4. The greatest majority of participants are Caucasian (76\%), with only one participant self-described in any other category. Two participants indicated more than one ethnicity, and no one reported being Hispanic or Pacific Islander. 
Table 4

Participants' Ethnicity

\begin{tabular}{lcc}
\hline Ethnicity/Race & $\mathrm{n}$ & Percentages \\
\hline Caucasian & 16 & $76 \%$ \\
Asian & 1 & $5 \%$ \\
African-American & 1 & $5 \%$ \\
Caucasian/Native American & 1 & $5 \%$ \\
Asian/Caucasian & 1 & $5 \%$ \\
Prefer not to answer & 1 & $5 \%$ \\
Pacific Islander & 0 & $0 \%$ \\
Hispanic & 0 & $0 \%$ \\
Native American & 0 & $0 \%$ \\
Other, please specify & 0 & $0 \%$ \\
\hline
\end{tabular}

Participants were next asked about their marital status. Only one answer selection was permitted for this question. All 21 participants responded to this question. Results are displayed in Table 5.

The mode of this particular set of data was the answer of "single, never married" by a large margin. Of the 21 participants, $90 \%$ reported they were single, never married, while one participant reported being married, and another preferred not to answer. People with ASD have difficulties in developing romantic relationships, so this is not altogether surprising (Muller et al., 2008). Also, the age range limitations (18-30) of this study may also have impacted the high number of single participants. 
Table 5

Participants’ Marital Status

\begin{tabular}{lcc}
\hline Marital Status & $\mathrm{n}$ & Percentages \\
\hline Single, never married & 19 & $90 \%$ \\
Married & 1 & $5 \%$ \\
Prefer not to answer & 1 & $5 \%$ \\
Widowed & 0 & $0 \%$ \\
Living with a partner & 0 & $0 \%$ \\
Divorced & 0 & $0 \%$ \\
Other, please specify & 0 & $0 \%$ \\
\hline
\end{tabular}

Participants were then asked to select the answer that best described their living situation. Of 21 participants, 20 responded to this question. Results are displayed in Table 6.

The answer of 'other, please specify' yielded an answer of "I rent a house and have a roommate." The most commonly selected answer to this question was "live with parents" (70\%), which is consistent with other research regarding people with ASD (Gutstein \& Whitney, 2002; VanBergeijk et al., 2008), which indicates that many with ASD will continue living at home with parents or caregivers. People with ASD often continue to require supports, or lack the type of employment that would enable them the financial freedom to live independently. 
Table 6

Participants' Living Situation

\begin{tabular}{lcc}
\hline Living Situation & $\mathrm{n}$ & Percentages \\
\hline Live with parents & 14 & $70 \%$ \\
Live on own & 3 & $15 \%$ \\
Live with my partner or spouse & 1 & $5 \%$ \\
Prefer not to answer & 1 & $5 \%$ \\
Other, please specify & 1 & $5 \%$ \\
Live in a group home & 0 & $0 \%$ \\
Living with an adult sibling & 0 & $0 \%$ \\
Live with my children & 0 & $0 \%$ \\
Live with my partner or spouse & & \\
and our children & 0 & $0 \%$ \\
Supported living & 0 & $0 \%$ \\
Living with roommates & 0 & \\
\hline
\end{tabular}

Participants were next asked to describe their current completed level of education. Of 21 participants, all 21 responded to this question. Results are displayed in Table 7. All the participants indicated they had at least a high school diploma, with $60 \%$ of participants indicating some type of training or education beyond high school. These data, while inconclusive, indicate that the participants in this study are at the higher-functioning end of the spectrum. 
Table 7

Participants' Level of Education

\begin{tabular}{llc}
\hline Current Education Level & $\mathrm{n}$ & Percentages \\
\hline High school student & 0 & $0 \%$ \\
High school graduate & 8 & $38 \%$ \\
Vocational or technical training & 2 & $10 \%$ \\
Associate's degree & 4 & $20 \%$ \\
Bachelor's degree & 4 & $20 \%$ \\
Master's degree & 1 & $5 \%$ \\
Doctoral degree & 1 & $5 \%$ \\
Prefer not to answer & 1 & $5 \%$ \\
Other, please specify & 0 & $0 \%$ \\
\hline
\end{tabular}

Participants were asked to select the option or options that best described their employment status. Participants were allowed to select more than one answer, therefore 30 responses were recorded. Participants selected a range of answers between one and four answers for this question. Responses of 'other, please specify' yielded answers of "unemployed, applying for disability pay; full time student, currently taking 4 classes and working on Honours research project." Results are displayed in Table 8.

Only $10 \%$ of participants reported having full time jobs. Since there were not follow up questions asked regarding employment, I cannot be certain if this is due to personal choice, or because they are seeking but cannot find full-time employment. Interestingly, one of the respondents who selected 'I work full time' also selected 'I am looking for work', perhaps 
indicating dissatisfaction with the participant's current employment opportunity. Of the four remaining participants who selected more than one answer, three reported they both volunteer and receive disability pay.

Table 8

Participants' Employment Status

\begin{tabular}{lcc}
\hline Employment Status & $\mathrm{n}$ & Percentages \\
\hline I work part time & 11 & $52 \%$ \\
I volunteer & 4 & $19 \%$ \\
I receive disability services/pay & 4 & $19 \%$ \\
I am unemployed & 3 & $14 \%$ \\
I work full time & 2 & $10 \%$ \\
Other, please specify & 2 & $10 \%$ \\
I work full time & 2 & $10 \%$ \\
Prefer not to answer & 1 & $5 \%$ \\
I have multiple jobs & 1 & $5 \%$ \\
\hline
\end{tabular}

Interview participants. Participants for the interview were selected by asking people to respond at the end of the survey if they would be willing to participate in a follow-up email interview for the study. Of the 21 participants, nine responded yes and provided an email address, ten responded no, and 2 skipped this question. Of the nine respondents who provided their email address, all nine were emailed informed consent (Appendix B) and the first set of interview questions (Appendix C). It was determined that in order to get the most informative responses that participants be given the questions over email, in order for them to be able to 
answer based upon their own schedule, and in a place of familiarity and comfort of their choosing. Utilizing email for the interviews also eliminated any potential communication barriers that a FTF interview may create. After the initial interview questions went out, only one response was received. A reminder email went out to the remaining eight participants, while the first interviewee received his second set of questions. The reminder email yielded two more responses. The first and second interviewees received and responded to three sets of four interview questions. The third interviewee responded to the first set of interview questions, but did not respond to subsequent emails.

\section{Ethical Considerations}

The first step in completing this research was seeking approval from Illinois State University's Internal Review Board. This procedure required me to name every potential risk conceivably associated with my study, and asked me to mitigate it as much as possible. Asking

people to disclose a disability is an ethical concern. There can be psychological stress associated with disclosing a disability, and answering questions regarding this disability. People with ASD may have wanted to participate, but not felt comfortable confirming their diagnosis to a stranger. It has been noted that people with disabilities sometimes do not wish to share about their disability online for fear of discrimination (Shpigelman \& Gill, 2014). In order to help mitigate this concern, participants were notified prior to participating via informed consent that they did not have to give their name or identifying information if they chose not to do so. The survey was anonymous, and people who volunteered to be contacted to provide additional information via interview are identified only by pseudonyms to protect their privacy. Participants were also informed that only the primary researcher has the information as to which participant matches the name in the study. The information will be kept for five years and then be destroyed. 
Additionally, people with ASD were asked to comment on or write about their Internet usage and report it to me. In some cases, people may have felt uncomfortable sharing information about this usage to a stranger. People were also asked to share their contact information if they wished to be contacted for follow-up questions in an interview, which may have led to concerns about their private information getting shared publically. To address these concerns, the survey results are only accessible to the researchers. After five years, online data will be deleted and data that were coded will be destroyed.

Additionally, providing information in a survey may be stressful to an adult with ASD. People with ASD generally tend to have anxiety (Jantz, 2011), therefore they may become overwhelmed or upset if they don't understand a question or they may have other reservations about completing the survey. To address this, the survey contained a caveat that the participant could skip a question or stop the survey at any time with no penalty or harm to the participant. This information was also shared with participants at the beginning of the survey as part of the informed consent. These precautions were put in place to lessen any anxiety or fears an individual may have had about participating.

\section{Instrumentation}

The primary instrument in this study was a web-based survey created to obtain specific information for this study. Survey research, which is a "numeric description of trends, attitudes, or opinions of a population by studying a sample of that population" (Creswell, 2013, Glossary), yields information needed to make generalizations from a sample to a population (Creswell, 2013). The survey consisted of closed and open ended questions to assess usage of CMC by those with ASD. Close ended questions had research based responses built into the survey to help alleviate anxiety in those with ASD. 'I prefer not to answer' was also an additional choice 
in case the participant became overwhelmed, did not understand, or did not feel comfortable sharing the requested information. Content covered using close ended survey questions included (a) demographic information, (b) types of CMC used (i.e., blogs, SNSs, support groups), (c) amount of time spent using $\mathrm{CMC}$, and (d) preferred types of CMC.

The survey also included open-ended questions. Information to be gained by these questions included (a) how people with ASD utilize CMC, (b) perceived benefits and challenges of using CMC, (c) overall experience in using CMC, and (d) additional supports needed for using CMC. The survey was created after a thorough search of the related literature and is loosely based off of other surveys that have been used with the target population (Benford, 2008; Gillespie-Lynch et al., 2014). The survey was a combination of drop down answers, matrixes, and open ended questions. The drop down responses regarding perceived benefits, challenges, and uses of $\mathrm{CMC}$ were rooted in the collected research on the subject regarding both the general population and those with disabilities. Survey validation was completed by having my dissertation committee read through the questions and provide feedback regarding the wording of the questions and the content. Additionally, it was field tested by asking people in the target sample group who are known to me to complete it prior to it being made available to the entire target population. The initial field test of the survey included three participants (two men, one woman), who orally answered each of the questions and provided feedback on each one. Two of the field tests took place FTF, and one was done via Google Hangouts. This pilot was completed based on the idea of cognitive interviewing, specifically utilizing verbal probing (Willis, 1999). As the primary researcher, I asked the respondent the survey question, asked the respondent if they understood it, or to explain it in their own words, and then had them answer it. The respondents were encouraged to give feedback regarding the structure and language of the 
survey questions. Changes were made to the wording and answer choices of several questions based on the feedback of the participants, but overall survey content remained the same.

After the initial field testing, the survey was active on Select Survey, and a number of individuals on the spectrum were invited to take the survey online to provide further feedback on the survey. The request "please provide any feedback you have regarding the design of this survey, including any questions you found confusing or hard to understand" was added to the end of the survey, however no significant issues were raised by any of the secondary field testers, and therefore no changes were made to the survey prior to it being released to the population.

In a qualitative study, the primary instrument is typically the researcher (Creswell, 2013). After reviewing the data collected in the survey, I reviewed and analyzed the information provided by participants. Since insufficient qualitative information was generated through the open ended questions to draw conclusions, I completed semi-structured interviews with participants who completed the survey and volunteered to be contacted for follow-up questions. Ten people indicated in the survey they were interested in follow up interviews, however only nine provided their email addresses. Of the nine contacted, only three responded, and only two of the three answered all the questions that were given to them. In these semi-structured interviews, I asked a combination of questions that were generated after seeing the results of the surveys and questions that had already been formulated. The purpose of the interviews was to elicit deeper responses than were provided by participants in the open-ended portions of the survey. 


\section{Data Collection Procedures}

Data collection was done by collecting both open and closed responses via survey by young adults with ASD. Data are stored mainly online by utilizing Select Survey. Collecting data in this way allows for the data to be password protected and isolated to a single account. Qualitative data were collected from the open-ended questions on the survey and via semistructured interviews. Similar to the interview guide approach (Johnson \& Turner, 2003), I interviewed people by using pre-planned topics, but gave myself the flexibility to reword or change questions as needed. This type of interviewing was appropriate for this study because I based my questions off of the survey data collected, and then formulated questions based upon the responses of the interviewees.

All interviews were done over email, and data collection was obtained through that means. An email address was created for the purpose of reaching out to potential participants and for participants to send their responses. Email was chosen as the method for the interviews due to the characteristics of the target population. An email was sent to participants who had indicated a willingness to be interviewed with a reminder about the study with the informed consent at the top. All interviewees started with the same set of first questions, and then each participant received a second and/or third round of questions based upon his/her previous responses. One participant did not respond after answering the first set of questions. The other two interviewees both received three sets of questions. After five years from the conclusion of the study, the interview information will be deleted from the email account, and ultimately, the email account will be deleted as well. Data collected from interviews that are printed, typed, or written will be stored in a locked cabinet to ensure confidentiality of participants. These data will be destroyed after a period of five years. 
Survey links were emailed to personal contacts of mine who could forward it on to others they know with ASD. Autism Speaks was contacted, and upon receipt of IRB approval, posted the link to the interview on their website. The founder of Urban Autism Solutions, Julie Tracy, sent the link to her contacts who work with young people with ASD. The link was also posted on Facebook and Twitter in order to make sure the largest amount of possible participants are reached. Data was collected over a period of several months. At that time, closed-ended responses were reviewed, and interview questions were revised based on the information collected and analyzed from the survey.

\section{Limitations}

Using a mixed methods design can lead to threats in validity of a study. In a convergent study, there are limitations because the amount of participants will likely differ. The number of participants who answered the close-ended questions was higher than the amount of participants who answered the open-ended questions. Additionally, the amount of semi-structured interviews completed was substantially lower than the number of participants in the quantitative portion of the study, meaning that the people who gave interviews may not reflect all the opinions of the larger group (Creswell, 2014). Additionally, interpretive validity, which is "the extent to which a researcher's interpretation of an account represents an understanding of the perspective of the group members under study" (Onwuegbuzie \& Teddlie, 2003, p. 354) is a threat to this study because I have attempted to interpret how the responses from the interviews and surveys indicate this group of people feels about using the Internet to communicate. However, this can be somewhat controlled for by identifying themes in the responses to look for patterns (Onwuegbuzie \& Teddlie, 2003). The two interviewees who provided information reported in this study were contacted via email and given an opportunity to review the conclusions that were 
drawn from their answers. Of the two interviewees, only one responded by noting that the conclusions did in fact accurately represent his views on using CMC, the other did not respond. Additionally, the very nature of a mixed methods design is to help control for validity, since combining quantitative and qualitative methods can help find one "true view" (Sandelowski, 2003, p. 328).

Survey design is a limitation in the present study, however this survey has been created specifically for use in this study, and was piloted twice with a sample group of the target population prior to distribution. Also, when using surveys, we are dependent on the participants who fill them out, and have to assume that they are being filled out honestly and reflect the true attitudes and beliefs of the participants.

In addition to threats to validity, there are other limitations to this study. To start, people with ASD are the intended participants in this study. However, there is no way to verify that all respondents are individuals with ASD. Next, the target demographic in this study is young adults. Again, since this survey is web-based, there is no guarantee that all participants are the age that they report to be on the survey. When using these data to make generalizations about this population, these limits must be kept in mind.

\section{Data Analysis Procedures}

In this study, the quantitative and qualitative data were collected simultaneously, then additional qualitative data were collected to help further explain or clarify the results of the quantitative data (Crewswell, 2013). Quantitative data was collected via close-ended survey questions, and has been analyzed using descriptive statistics. Descriptive statistics, "statistical procedures used to summarize, organize, and simplify data" (Gravetter \& Wallnau, 2013, p. 7) are useful for taking data and making it easier to read and understand (Gravetter \& Wallnau, 
2013). Information such as the frequency of each answer, the distribution of answers from each question, and the mode of responses has been analyzed and reported.

Qualitative data were collected via open ended survey questions and analyzed using a grounded theory approach. Grounded theory is a qualitative inquiry design in which the researcher forms a theory based upon the viewpoints of the participants after analyzing and collecting data (Creswell, 2014). Open coding was the beginning of the analysis. I began by looking for words and phrases that had similarities, and then moved onto thematic coding. The method for categorizing data I used for this study is In Vivo coding (Saldana, 2016). This method is often used when trying to determine the experiences and personal meanings found within qualitative data, and is also considered part of the coding canon of grounded theory (Saldana, 2016). Additionally, this allowed me to use direct quotations of participants in my study. This is particularly valuable in this study because people with ASD regularly see themselves as the experts on their needs, and may find this study more meaningful than if they are reading the paraphrasing of data by a researcher (Griffith et al., 2011). Once both types of data were analyzed, they were merged via a side-by-side comparison (Creswell, 2014). The statistical results were noted, and the qualitative themes were analyzed to confirm the quantitative results. I used this process to draw conclusions about the perceived benefits and challenges in using $\mathrm{CMC}$ for young adults with $\mathrm{ASD}$, and also to make recommendations for future research.

\section{Researcher Positionality and Reflexivity}

To be transparent, I must disclose my motivations for research. I have a strong interest in the direct voices of young adults with ASD because I believe they are often overlooked. In my experience as a family member of someone on the spectrum and as an educator, since people 
with ASD have difficulties with communication they often allow others to speak on their behalf. This research topic was motivated by a desire of mine to hear from those with ASD in their own words what their perceptions and needs are surrounding this topic. When designing this research study, my own assumptions were that people with ASD may prefer to use CMC to interact with others and that they may desire for explicit training in utilizing different websites or SNSs to connect with other people, both on and off the spectrum. Acknowledging this personal bias prior to collecting data helped me to keep this bias out of the data analysis process as I looked through and categorized data. Using the strategy of reflexivity, I have "actively engage[d] in critical selfreflection about [my] potential biases and predispositions" (Johnson, 1997, p. 103).

After coding the open-ended survey data for the first time, I discussed my findings with a colleague who is experienced in qualitative research prior to re-coding data and drawing conclusions. After discussion, this colleague and I confirmed that despite my pre-conceived notions, she and I had coded the data similarly. I also looked for examples of "negative case sampling" (Johnson, 1997, p. 103) to make sure that I carefully examined for information that would discredit my findings.

\section{Ensuring Reliability and Validity}

Reliability and validity in mixed methods studies are, in part, covered by using two different research methods that cover the other's weaknesses. However, ensuring reliability and validity in a qualitative study does differ from in a quantitative study. Reliability comes from repetition; I utilized a survey that has never been used before, but is modeled off of similar surveys and was field tested with the target population and then revised. I also used strategies such as triangulation and peer review to help ensure different types of validity in my study. 
It is important that the views and conclusions that I come to are representative of the group and that I do not inaccurately portray conclusions the participants did not intend. Having participants give feedback on my findings may help to make sure that I have not misunderstood or misconstrued information in the open ended sections of the survey, however, since this survey is anonymous, I was unable to follow-up with each participant. However, as I had the email addresses of the interviewees for this study, I emailed the data reported in this study specific to the interviewee to have them review it for accuracy. Although Greg (pseudonym) did not respond to this request, Steve (pseudonym) did and confirmed that the data reported was an accurate reflection of his answers. Another way to ensure interpretive validity is by using direct quotations from the participants themselves, thereby minimizing the effect my paraphrasing would have on the meaning and outcomes (Johnson, 1997).

Theoretical validity applies to how and why a theory can explain a particular phenomenon (Johnson, 1997). This can be ensured by using peer review. I have utilized peer review by asking colleagues and peers to listen to my explanations as to how and why young adults with ASD are using CMC. They would then look for possible problems with my theories, leading me to re-examine my data or to look for additional data. The aforementioned strategy of negative case sampling was also useful in making sure that I haven't used my data to fit my own, preconceived notions when determining my conclusions.

Triangulation is also be a strategy utilized in this study to help determine validity. While there are different types of triangulation, in this study I used methods triangulation. Methods triangulation refers to using different types of methods to collect data. Using these different methods will allow me to collect more and different types of evidence to draw my conclusions, therefore making a stronger case (Johnson, 1997). 


\section{CHAPTER IV: FINDINGS}

The purpose of this study was to determine how people with ASD utilize CMC. Data were collected through both an online survey and through follow-up interviews with interested participants. The survey link was made available and distributed in a variety of ways. To start, the link was emailed to various contacts who work with people on the spectrum. The link was also shared on Facebook and Twitter, and on the research page of the Autism Speaks website. The survey was actively promoted for approximately two months (August 26-October 28), but open and available until December 23. The last question of the survey asked people if they were interested in being contacted for a follow-up interview. People who responded "yes" to this question were then asked to provide an email address where they could be contacted. Emails to interested interview participants were sent in mid-October.

\section{Usage of CMC}

In order to answer the research questions posed by this study, underlying issues regarding how people with ASD use computer mediated communication tools needed to be addressed. Consequently, many questions were asked of participants to determine which types of CMC they use, how they use them, and the frequency of this use.

Participants were first asked to select which CMC modalities they use to communicate with family, friends, or others. Participants were allowed to select all that applied, resulting in a range of answers between one and six. All 21 participants responded to this question. Since this question allowed participants to choose more than one answer, 58 responses were recorded.

The top three most common types of CMC utilized by participants as demonstrated by the data presented in Table 9 are email (90\%), social networking sites (62\%), and special interest websites (52\%). The least common were advocacy websites and advocacy chatrooms, which 
were not selected by any participants, followed by forums (4\%) and Skype (4\%), as these answers were provided via the 'other, please specify' option. Results of the data based on the 21 participants who responded to this question have a tied mode of one response provided and three responses provided $(n=6)$. Of the participants who only selected one response, $83 \%$ selected 'email' while the remaining participant chose 'prefer not to answer'.

Table 9

Reported Usage of CMC Types

\begin{tabular}{lcc}
\hline CMC Type & $\mathrm{n}$ & Percentages \\
\hline Email & 19 & $90 \%$ \\
Social networking sites & 13 & $62 \%$ \\
Special interest websites & 11 & $52 \%$ \\
Blogs & 6 & $29 \%$ \\
Dating websites & 3 & $14 \%$ \\
Special interest chatrooms & 3 & $14 \%$ \\
Other, please specify & 2 & $10 \%$ \\
Prefer not to answer & 1 & $5 \%$ \\
Advocacy websites & 0 & $0 \%$ \\
Advocacy chatrooms & 0 & $0 \%$ \\
\hline
\end{tabular}

Although in this question no participants selected that they use advocacy websites or chatrooms to communicate with others, qualitative data collected from later questions in the survey indicate that at least one participant uses the Internet for advocacy. In response to the 
request 'Describe your overall experience with using the Internet to communicate', eighteen people responded, with one participant writing "I think my using the internet has helped in my advocating," and another who wrote "I am a well-respected leader in social justice advocacy on Twitter and Facebook." This information indicates that while participants may not be using specific advocacy websites, there are other outlets online that are being utilized for advocacy.

Participants were next asked to disclose how often they participated in certain activities using computer mediated tools in the past two weeks. All 21 of the survey participants responded to at least some portion of this question. Data presented in Table 10 indicate that people with ASD are using the Internet to interact with people they already know, and some are using the Internet to meet and interact with new people as well. Of 20 respondents, $45 \%$ indicated they interact with known people online every day, with $0 \%$ reporting they hadn't done this at all in the past two weeks. Comparatively, six people (29\%) who responded to this question indicated that they had not used the Internet to meet and interact with new people in the past two weeks, while all remaining participants who responded to this question reported using the Internet for this purpose at least once.

Although they may be communicating with others, data indicate young people with ASD are not using the Internet to reach out and communicate with others on the spectrum as often as they communicate with other people. Only two participants (10\%) indicated this is something they do every day, and nine reported (45\%) not having done it in the past two weeks at all. The remaining participants indicated either this is something they had done only once in the past two weeks $(30 \%)$ or between 5-10 times (15\%). 
Table 10

Frequency of Various Activities Using CMC in a Two Week Period

\begin{tabular}{|c|c|c|c|c|c|c|}
\hline Activity & $\mathrm{n}$ & $\begin{array}{c}\text { Not at } \\
\text { All }\end{array}$ & $\begin{array}{c}\text { At least } \\
\text { once }\end{array}$ & $\begin{array}{c}5-10 \\
\text { Times } \\
\end{array}$ & $\begin{array}{c}\text { More than } \\
10 \text { times }\end{array}$ & Everyday \\
\hline $\begin{array}{l}\text { Interact with people } \\
\text { you already know }\end{array}$ & 20 & $0 \%$ & $25 \%$ & $15 \%$ & $15 \%$ & $45 \%$ \\
\hline $\begin{array}{l}\text { Meet and interact } \\
\text { with new people }\end{array}$ & 21 & $28.8 \%$ & $42.9 \%$ & $9.5 \%$ & $4.8 \%$ & $14.3 \%$ \\
\hline $\begin{array}{l}\text { Find someone to talk } \\
\text { to who has ASD }\end{array}$ & 20 & $45 \%$ & $30 \%$ & $15 \%$ & $0 \%$ & $10 \%$ \\
\hline $\begin{array}{l}\text { Advocate for yourself } \\
\text { or others }\end{array}$ & 21 & $38.1 \%$ & $23.8 \%$ & $19.1 \%$ & $4.8 \%$ & $28.6 \%$ \\
\hline $\begin{array}{l}\text { Participate in an } \\
\text { online discussion }\end{array}$ & 21 & $47.6 \%$ & $0 \%$ & $19.1 \%$ & $4.8 \%$ & $28.6 \%$ \\
\hline $\begin{array}{l}\text { Read other people's } \\
\text { posts }\end{array}$ & 21 & $23.8 \%$ & $9.5 \%$ & $0 \%$ & $19.1 \%$ & $47.6 \%$ \\
\hline $\begin{array}{l}\text { Look at other } \\
\text { people's pictures }\end{array}$ & 20 & $20 \%$ & $25 \%$ & $0 \%$ & $10 \%$ & $45 \%$ \\
\hline $\begin{array}{l}\text { Find people with } \\
\text { similar interests }\end{array}$ & 21 & $38.1 \%$ & $19.1 \%$ & $14.3 \%$ & $4.76 \%$ & $23.8 \%$ \\
\hline
\end{tabular}

Participants were also asked to note how many times in the past two weeks they had used the Internet to make plans to meet someone FTF or to look for employment opportunities. All 21 participants responded to this question. Results for this question are presented in Table 11. Data presented in Table 11 indicate differing opinions for using the Internet to make plans for meeting FTF and for looking at employment opportunities. While the majority of participants picked "not at all" for both (48\% for making plans and 57\% for looking for employment), there were participants who indicated they used the Internet for both of these activities everyday (14\% for meeting people face to face, and 14\% for looking for employment). 
Table 11

Frequency of Using the Internet to Make Plans or Find Employment in a Two Week Period

\begin{tabular}{lcccc}
\hline Activity & Not at all & At least once & $5-10$ times & Everyday \\
\hline $\begin{array}{l}\text { Make plans to meet someone face } \\
\text { to face }\end{array}$ & $47.6 \%$ & $14.3 \%$ & $23.8 \%$ & $14.3 \%$ \\
$\begin{array}{l}\text { Look for employment } \\
\text { opportunities }\end{array}$ & $57.1 \%$ & $23.8 \%$ & $4.8 \%$ & $14.3 \%$ \\
\hline
\end{tabular}

Participants were then asked to indicate if they had accounts on various SNSs, and if so, how often in the past two weeks they had logged into these sites. Again, all twenty-one participants responded. Results are detailed in Table 12.

Although 13 participants indicated they use SNSs to communicate with others in a previous survey question, many participants indicated they do not have an account on many social networking sites such as Twitter (52\%), Facebook (38\%), or LinkedIn (67\%). Of the people who do access these sites, some reported in the past two weeks that they have logged into the sites ten times or less: Twitter (30\%), Facebook (19\%), and LinkedIn (24\%). Other reported they had used these same sites 11 times or more in the past two weeks: Twitter (19\%), Facebook (38\%), and LinkedIn (5\%). Overall, it appears of the SNSs, Facebook is the one most frequently utilized by participants, while LinkedIn is accessed with the least amount of frequency.

Interestingly, based on the data collected, it appears that users most commonly a) did not have an account for a particular site, b) rarely engaged with the site (1-5 times in two weeks) or c) visited the site frequently (more than 20 times). Based on this data, participants rarely responded that they interacted with SNSs moderately; the data seem to indicate that an all-ornothing approach is more the norm for the majority of sites. 
Table 12

Frequency of Use of SNSs in a Two Week Period

\begin{tabular}{lccccccc}
\hline SNS & No & & & & & \\
Twitter & Account & 0 & $1-5$ & $6-10$ & $11-15$ & $16-20$ & Everyday \\
Facebook & $52.4 \%$ & $9.5 \%$ & $9.5 \%$ & $9.52 \%$ & $0 \%$ & $0 \%$ & $19 \%$ \\
Myspace & $38.1 \%$ & $4.8 \%$ & $14.3 \%$ & $0 \%$ & $4.8 \%$ & $0 \%$ & $38.1 \%$ \\
Google+ & $76.2 \%$ & $0 \%$ & $4.8 \%$ & $0 \%$ & $0 \%$ & $0 \%$ & $9.5 \%$ \\
LinkedIn & $28.6 \%$ & $38.1 \%$ & $14.3 \%$ & $0 \%$ & $0 \%$ & $4.8 \%$ & $14.3 \%$ \\
Instagram & $66.7 \%$ & $9.5 \%$ & $14.3 \%$ & $0 \%$ & $0 \%$ & $4.8 \%$ & $4.8 \%$ \\
Tumblr & $71.4 \%$ & $0 \%$ & $9.5 \%$ & $4.8 \%$ & $0 \%$ & $0 \%$ & $9.5 \%$ \\
Snapchat & $66.7 \%$ & $9.2 \%$ & $4.8 \%$ & $0 \%$ & $0 \%$ & $4.8 \%$ & $14.3 \%$ \\
\hline
\end{tabular}

The number of SNSs participants in this study have an account for varies widely as well. An individual analysis of the survey questions indicated that $14 \%$ of participants have an account on all of the websites listed in Table 12, while 14\% reported have no accounts for any of these sites. A percentage of participants (19\%) only reported an account on one site; these sites were either Facebook $(n=2)$ or Google $+(n=2)$. Results are presented in Table 13.

Many participants indicated they have an account for Google+, which may have been construed as email, or Gmail. Regardless, Google+ was the most commonly reported SNS in which participants had an account (71\%), followed by Facebook $(62 \%)$ and Twitter (48\%). The sites with the least amount of accounts reported by participants were Instagram (29\%), LinkedIn (29\%) and MySpace (24\%). 


\section{Table 13}

Number of SNS Accounts per Participant

\begin{tabular}{ccc}
\hline $\begin{array}{c}\text { Number of } \\
\text { SNS Accounts }\end{array}$ & $\begin{array}{c}\text { Number of } \\
\text { Participants }\end{array}$ & Percentages \\
\hline $\begin{array}{c}1 \\
2\end{array}$ & 3 & $14 \%$ \\
3 & 3 & $19 \%$ \\
4 & 2 & $14 \%$ \\
5 & 2 & $10 \%$ \\
6 & 1 & $10 \%$ \\
7 & 2 & $5 \%$ \\
8 & 1 & $10 \%$ \\
\hline
\end{tabular}

Participants were asked to describe their overall experiences with using the Internet to communicate. Qualitative data indicate that the majority of participants see more benefits than challenges when using the Internet to communicate. Eighteen participants responded to this question. Five of them either declined to answer (provided an answer of "n/a") or indicated a neutral response (“It has been ok.”). Only one participant's answer indicated overall dissatisfaction with using the Internet to communicate, but still noted the positives: "It has been difficult, as it is much easier to type and not talk and not have to understand body language, communication skills are still need[ed]. Just like in the real world it is hard sometimes to know where to go and some groups you think should exist don't." The remaining participants all 
primarily responded with positive remarks regarding their overall experiences when using the Internet to communicate. Two of the most commonly cited benefits were making friends and staying connected with existing friends:

- "The Internet led me to all of my best and close friends."

- "I've used it for over a decade to keep in contact with family and friends."

- "I have made most of my friends through Twitter."

and the benefits of email and the ease of written communication:

- "I find emails extremely useful."

- "I find that I am misunderstood far less often and I make people angry less often"

- "Generally better than speaking in real life, where I tend to stumble on words."

The remaining comments indicated that people enjoy using the Internet for entertainment or for purposes of advocacy.

These qualitative data support the quantitative information provided by participants. It appears that using the Internet to stay in touch with others, particularly family and friends, is one of the main reasons people with ASD use the Internet. Making new friends and connecting with others that one could not meet in real life came up less frequently, but for the participants who wrote about it, they stated it was a very important benefit to them, with one participant stating, "I've formed a closer bond with people I've met online than with people I've known my whole life."

In addition to the benefit of ease of communication, the Internet has provided other benefits to some participants. One participant mentioned that use of the Internet led to employment. Another noted that (s)he has a forum and a blog, and also codes games. A different participant stated that, "I think it delayed my diagnosis because I have many close 
friends and a strong support system. However, I struggle with developing friendships through more conventional settings." While a couple of people indicated they do not use the Internet for social communication (only functional) a couple of others stated the importance of the communities they've met online. Based on this information, it appears that while many find value in utilizing the Internet, it is to varying degrees and for a plethora of reasons.

\section{Perceived Benefits of CMC}

Participants were asked to select all the benefits they feel they gain from using online communication, with an option to type in their own answer (other, please specify). Of 21 participants, all 21 answered this question. Participants were allowed to select as many benefits as they wanted, and participants selected between one and seven perceived benefits, which led to a total of 83 responses recorded for this question. Results are displayed in Table 14.

Unsurprisingly, the most frequently selected answer was being able to respond when desired (62\%), followed by having a greater amount of time to formulate a response (54\%), and not having to read or interpret body language or nonverbal cues (50\%). Three participants chose 'other, please specify' which yielded responses of "allowing the other person to reply at their leisure so I know I'm not imposing; ability to send links to pertinent info; I read email'" Since FTF communication can be particularly difficult for those on the spectrum, it is unsurprising that many participants selected these as benefits to communicating using the Internet. Having to respond immediately and off the cuff while also reading/interpreting body language are all components of communication that can make interacting with others difficult for those on the spectrum.

Analysis of the surveys individually indicate that some of these answers go hand-in-hand. Being able to respond when desired and greater amount of time to form a response were the most 
commonly selected answers, and each individual who selected 'greater amount of time to form a response' also selected 'being able to respond when you want', which indicates that for those who need a greater amount of time to formulate a response, not feeling pressure to respond right away is also a valued feature of CMC. Additionally, of the 12 participants who selected 'opportunities to meet others you couldn't meet face to face' and the 11 who selected, 'being able to stay connected to family and friends', ten of them selected both of these answers. This may indicate that the participants who selected these answers see value in meeting people online, and possibly maintaining relationships with the new people they meet online.

When looking at the number of benefits participants selected, the range is one to six, the mode is six responses $(n=5)$, and the mean is four. When selecting answers for this question, $38 \%$ of the 21 participants selected three or less benefits, while the remaining participants $(62 \%)$ picked four or more benefits. Also, when analyzing the individual responses, of the four participants who only selected one answer for this question, three of them picked 'prefer not to answer' and the fourth picked 'other' and wrote in "I read email." This indicates that perhaps the participants who only selected one answer may find benefits in using CMC, but were not comfortable sharing their thoughts on this survey. 
Table 14

Reported Benefits of Using CMC

\begin{tabular}{llc}
\hline Benefits & $\mathrm{n}$ & Percentages \\
\hline $\begin{array}{l}\text { Being able to respond } \\
\text { when you want }\end{array}$ & 16 & $62 \%$ \\
$\begin{array}{l}\text { Greater amount of time } \\
\text { to form a response }\end{array}$ & 14 & $54 \%$ \\
$\begin{array}{l}\text { Not having to read or interpret } \\
\text { body language or nonverbal cues }\end{array}$ & 13 & $50 \%$ \\
$\begin{array}{l}\text { Opportunities to meet others } \\
\text { you couldn't meet face to face }\end{array}$ & 12 & $46 \%$ \\
$\begin{array}{l}\text { Being able to stay connected } \\
\text { to family and friends }\end{array}$ & 11 & $42 \%$ \\
$\begin{array}{l}\text { Being able to type or write } \\
\text { responses instead of speaking }\end{array}$ & 11 & $42 \%$ \\
$\begin{array}{l}\text { Prefer not } \\
\text { to answer }\end{array}$ & & $12 \%$ \\
$\begin{array}{l}\text { Other, } \\
\text { please specify }\end{array}$ & 3 & $12 \%$ \\
\hline
\end{tabular}

Participants were then asked via open ended question to pick the one benefit they find to be the most important to them. Of 21 participants, 18 provided an answer to this question. The qualitative survey data collected support the frequency of answers picked in the previous question. Half of the 18 participants who provided answers for this question indicated they felt using online communication was beneficial to them because of how they are able to respond to others; there were a variety of reasons they find this beneficial, such as:

- "responding when I want, because sometimes I just want to escape a conversation" 
- "being able to respond when you want... with autism, sometimes to[o] much interaction can change our emotional state...with online communication you can better control this"

- "typing instead of speaking because it is harder for me to talk than type"

- "it's hard right away to think of the best way in saying a response to someone"

An additional benefit that wasn't listed as an option in the previous question, but perhaps is a by-product of having greater time and flexibility to respond is a reduction of stress when communicating.

- "in person I feel pressured to respond right away"

- "it’s less stressful than speaking when I am overwhelmed"

- "I feel that the addition of extra time is critical. In a conversation, one must formulate a response instantaneously, which is not a reasonable expectation of many people with developmental disabilities. I get by well enough, but it is tiring."

Later in the survey, participants were asked to share the benefits they have experienced when using the Internet to communicate via an open ended question. This question elicited similar responses in participants to previously asked questions. For various reasons, the many freedoms in which one can respond and keep in touch with others when using the Internet was mentioned as an important benefit for many participants:

- "easier social 'rules' to understand"

- "It is easiest for me to keep up the level of contact needed to maintain relationships through frequent casual online chat."

- "I can wear pajamas and a silly hat and nobody is the wiser."

- "It allows for communication over long distances at high speeds, and unlike the telephone an instantaneous response is not required." 
- "Having friends who don't expect me to muster up the energy to hang out regularly or call them on the phone or respond to their text message right away after they're sent is also cool. My online friends understand better than anyone."

The second most commonly mentioned benefit was finding other people with similar interests. Many participants noted that this was benefit they have experienced when using the Internet to communicate.

\section{Perceived Challenges of CMC}

Participants were asked to select all the challenges they feel they face when using online communication, with an option to type in their own answer ('other, please specify'). Of 21 participants, all 21 responded to this question. Participants were allowed to select as many challenges as they wanted, which led to a total of 41 responses recorded for this question (which is less than half the responses recorded for benefits). Between one and six responses were selected by participants. Results are displayed in Table 15.

Data presented in Table 15 indicate concern about online privacy was the greatest among participants who answered this question (38\%). The next greatest challenge selected by participants was concern about being taken advantage of online (27\%). These challenges go hand-in-hand, and both fall under the larger concern of not being able to trust everything or everyone on the Internet. Three participants chose 'other, please specify' which yielded responses of "deciding which websites are safe; dealing with a**holes; From a social perspective, there is more opportunity for misinterpretation, for statements to be interpreted as carrying hostile or other negative intentions. Without the clarity provided by nonverbal communication (if one ignores the time demands accompanying a face-to-face conversation, the nonverbal language is actually a very useful method), participants in online interactions may end 
up creating conflicts where none exists, or at least experiencing some form of misunderstanding". While the Internet can be a place of great opportunity to communicate, learn, and collaborate, people (especially those with disabilities) must be savvy when utilizing it. Of 21 participants, only $14 \%(n=3)$ selected more challenges to utilizing CMC than benefits. When looking at how many challenges were selected by each participants, the mode is one (11 responses). When looking at the responses, of the participants who selected only one answer, $45 \%$ selected an answer of 'none', while $18 \%$ selected 'prefer not to answer'.

Additionally, of the ten participants who selected 'concern about online privacy' and seven who chose 'concern about being taken advantage of online', five chose both.

Table 15

Challenges of Using CMC

\begin{tabular}{lcc}
\hline Challenges & $\mathrm{n}$ & Percentages \\
\hline Concern about online privacy & 10 & $38 \%$ \\
Concern about being taken advantage of while online & 7 & $27 \%$ \\
None & 5 & $19 \%$ \\
$\begin{array}{l}\text { Finding people to communicate with who share } \\
\text { similar interests }\end{array}$ & 4 & $15 \%$ \\
$\begin{array}{l}\text { Concern that spending too much time online means } \\
\text { less time for your offline relationships }\end{array}$ & 4 & $15 \%$ \\
$\begin{array}{l}\text { Finding people to communicate with who share } \\
\text { similar experiences }\end{array}$ & 3 & $12 \%$ \\
Prefer not to answer & 3 & $12 \%$ \\
Other, please specify & 3 & $12 \%$ \\
Navigating different websites & 2 & $8 \%$ \\
\hline
\end{tabular}


Participants were then asked to select the greatest challenge in communicating online from the responses they picked in the previous question in an open ended survey question. Of 21 participants, 14 participants answered this question. The qualitative data survey supports the information obtained in the previous question. Of the 14 people who responded to this question, four of them indicated the biggest challenge of using the Internet are concerns regarding privacy and/or being taken advantage of by someone they do not know.

- "I have to be very careful when giving personal information to other people"

- "I do not want clients to have large amounts of personal information about me"

- “...even when talking to one person, they may tell others about you"

- "When you are with someone face to face you have a better understanding of how they will respond versus interaction online when you only have their words."

The remaining ten respondents all had different perspectives on what the greatest challenge of using the Internet for communication is. Other answers provided included not knowing the person, fear of losing social skills "by talking to a screen all day", and an inability to find someone else with ASD to communicate with online. Participants also provided answers that were not given as options in the previous question. Other challenges include that it can be hard to start a conversation with someone they do not know, communicating online "goes too fast", obstacles of miscommunication, and dealing with people who are rude or insulting. Interestingly, with the exception of the concerns regarding privacy, almost every answer for this question was unique to the respondent.

Later in the survey, participants were asked to share the challenges or drawbacks they have experienced when using the Internet via an open ended question. Of the 21 participants, 16 answered this question. Again, there were many different answers provided by participants for 
this question. However, while privacy concerns remained an issue noted by some, more participants indicated that concerns over misinterpretation were a challenge more than anything else. Fear of either being misunderstood or misunderstanding the intent of others was the most common theme in this set of responses:

- "Some people don't always understand that their tone is not transmitted in text. And it's possible to read something someone might say with a tone other than they intended."

- "I have even a harder time online trying to figure out sarcasm and satire."

- "While I appreciate being on level playing field in that no one can see nonverbal cues online, it can also lead to misunderstandings."

Privacy and finding trusted websites was the second most common theme in this set of responses. One participant noted that people with autism in particular could be vulnerable to Internet shaming if information they share privately becomes public, or if they are ill-advised to share information online. Other drawbacks included the lack of real 'personal' contact - lack of physical touch, not hearing a voice, logistics such as needed to keep an Internet connection/device to respond, getting in trouble from a parent for spending too much time online, or feelings of inadequacy when seeing the accomplishments or milestones of others posted online.

\section{CMC Support Needs}

Participants were asked an open ended survey question asking them if there are computer mediated communication tools or websites they are not currently using that they would like to use, and if so, what supports or assistance would they need to access these websites.

This question elicited 14 responses, and of those, half did not provide an answer indicating they'd like to utilize any additional online communication sties they are not currently 
using ("Idk" "n/a" "I cannot think of any tools or websites I would like to use.") The remaining answers indicated a need to learn the social norms when navigating websites, how to find relevant or useful sites, or a one-on-one helper.

Participants were also asked what supports they would need to minimize the challenges they named in the survey, via an open ended survey question. Although this question only yielded seven responses out of 21 participants, data from that question indicate a need for different opportunities:

- "list of trusted blogs"

- "more autistic sites, maybe even make some for just communities"

- "finding like-minded chatrooms and blogs"

- "I need someone besides my mom to help me"

- "More social opportunities"

- "More opportunities for secure communications...I would also like more opportunities for content to be deleted from the Internet at the author's discretion."

\section{Interviews}

Interviewees were participants who indicated on their surveys they were interested in participating in follow-up email interviews. Although nine people provided their email addresses, only three ultimately responded to the interview questions. Of these three, two participants answered all three sets of interview questions. As qualifying information and demographic information was collected within the survey, no further identifying information was obtained from these respondents. Each of them are identified with pseudonyms in this study, and each participant's specific interview questions are detailed in Appendix C. 


\section{Greg}

Greg immediately responded to my initial email regarding the interview. He is a white male between the ages of 25-27. His answers indicated that while he noted the many challenges that people with ASD face in utilizing $\mathrm{CMC}$, he believes $\mathrm{CMC}$ is in an important tool for those on the spectrum. Greg uses CMC in a variety of ways, and for different purposes. He utilizes email to communicate with others, both personally and professionally. He also uses forums, such as City Data, to interact with others (both on and off the spectrum) and has used Facebook to share photos and to react to the posts of others.

Greg notes many challenges, specifically for people with ASD, when communicating online. Concerns include people having too much of your personal information, online harassment/bullying, being scammed or persuaded to take the viewpoints of others, having personal information sold or given to other websites, and becoming 'rusty' on FTF social skills. Based on his responses, Greg values his online privacy. It seems that one of Greg's main concerns is that people with ASD could potentially be penalized or harmed in some way, if employers or others find out that an individual is on the spectrum. He states "it is important to many autistics that their employer not know about their condition." Greg mentions various ways he ensures against being identified online such as not revealing specific information about himself, using websites he doesn't believe employers would use to determine if someone was on the spectrum, or giving information to different websites with various spellings of his name to see if junk mail comes to him with that name.

Greg notes that just like in FTF communication, people with ASD can be misunderstood when communicating online. He believes that people with ASD are routinely not taken seriously in FTF interactions, or have difficulty in finding support from others. However, in an online 
situation, some of these concerns can be mitigated by having the extra time to formulate responses, and by having the support of others on the spectrum. Greg feels that using online communication is helpful, but that life cannot be lived "online", and that people with ASD should not utilize it at the expense of working to strengthen skills in FTF communication. In addition to online privacy and being misunderstood, there are other concerns with communicating online. Greg states that he used to be on Facebook, but does not use it anymore. His concerns include that Facebook is a website that he feels employers use to investigate employees and potential hires, that it can be used to connect people who perhaps wish to remain anonymous, and that it can be confusing due to the frequency and variation of posts that one is exposed to on their page. Additionally, Greg has concerns that "no one does anything for nothing, there is always a reason," leading him to believe that if employers or companies seek to friend you or ask for your support online, they may be not be benign in doing so. Greg values sites that allow users to participate but remain anonymous, such as City Data and Wrong Planet.

Despite these challenges, Greg states the benefits to using CMC for people on the spectrum, reiterating several times that he feels using this method of communication is "an invaluable tool" for those on the spectrum. The many benefits he experiences include being more efficient in communicating, being able to interact with others on the spectrum, building confidence in communication, and allowing people to be honest and open in their responses.

Greg finds email beneficial for both personal and professional reasons. He notes that it is easier to communicate in this way as he has "less energy and concentration going into deciphering body language and phrases." He also likes being able to reference previous emails to remember important details, and to ensure that he can defend or rationalize choices made at work. Communicating online also allows people on the spectrum to "go back over and recheck 
our work" which can make communication easier. Greg prefers the City Data Forum to many other sites because of the way it's organized, threads that keep "conversations from getting stale", and features such as being able to direct message others who share similar interests, and also block people who may be unkind. Greg also notes that this site has allowed him and others to find an online autistic community, and that for many people with ASD, online communities are the only ones they have.

\section{Steve}

Steve responded to the request for an email interview after a reminder email was sent to him. He is a white male between the ages of 22-24. His answers describe a person who uses CMC primarily for functional communication and advocacy. Steve uses both email and Facebook, and describes his participation on Facebook as "inevitable, the way our society is going." Primarily, Steve currently uses Facebook to consult with others in his educational program, and to promote an ASD group in which he both participates and helps to facilitate.

Steve mentions the resistance he feels at any sort of change, no matter how small. For example, he feels he may someday join LinkedIn, but delays for no specific reason other than it is a change. He also states that he eventually may use Facebook for a more social purpose in the event he moves and needs it to stay in touch with people in his current area. The idea of how people on the spectrum may change over time seems to be an area of interest to Steve, and he mentions more than once how he cannot predict his future actions.

Based on his responses, Steve seems to value $\mathrm{CMC}$ and the opportunities it provides to both better understand ASD and to help advocate for those on the spectrum. For example, he states that when using the Internet, the activity that absorbs most of his time is researching academic articles in order to learn more about the different domains of ASD. Study of ASD and 
how it is understood appears to be of great importance to Steve; he has a strong belief that the medical/clinical model of ASD is "not going to encourage high self-esteem from individuals." Rather, he believes that a positive understanding combined with interventions "has the potential to promote greater happiness and quality of life, as well as to reduce stress and promote better self-efficacy and better adaptive functioning." Although he has experience writing and sharing online about ASD, discussing his own experiences with ASD online has not always been a high priority due to other commitments (such as his education). Steve states that despite this, he is very committed to the idea of not only sharing his own views regarding how ASD is perceived and understood by others (i.e. the medical model), but in helping others find and share their voices as well. As he puts it, "how can we expect typically-developing people to respond to the marginalization and exclusion of people with ASD if they never hear what we have to say?"

Steve also references other benefits of using $\mathrm{CMC}$ for those on the spectrum. For example, he notes that people in rural areas "might not find themselves with like-minded peers immediately nearby." He also notes that technology has been responsible in the past for allowing what he calls "nerdish subcultures" to emerge, which could be expanded to include those on the spectrum, thereby promoting greater advocacy for this group. He also enjoys looking at blogs and informational website regarding ASD to learn new information or about upcoming events.

In addition to the benefits, Steve briefly mentions potential concerns when communicating online. He notes that he does not typically interact with people online he doesn't already know, which mainly alleviates the concern that he would encounter an online conflict based on something he posts. If this should occur, Steve believes he would hide his Facebook page from the individual. Steve notes that he is "simultaneously very conservative about sharing 
information related to my private life, yet also very open about my diagnosis." While he believes there is some concern that having his diagnosis of ASD could potentially impact his future employability, his belief in advocacy outweighs this concern. However, Steve does state that he is extremely careful in what he shares online in an effort to make sure he does not post anything "potentially embarrassing or politically incorrect."

The third interviewee, a white male between the ages of 25-27, did not provide sufficient information to draw conclusions regarding his perceived benefits or challenges in using CMC. His brief responses indicated that he uses CMC to "make plans with friends," however setting up/using a SNS is "too much work" and that he is "not interested" in using CMC to connect with others who have ASD (he noted he would prefer to do this in person).

\section{Triangulation of Data}

Despite the small sample size, these data all work together to support the claim that those with ASD find more benefits than challenges to using CMC. The quantitative and qualitative data collected from the survey combined with the anecdotal evidence from the interviews all corroborate the notion that using $\mathrm{CMC}$ is a powerful tool for those on the spectrum to communicate with others by reducing some of the social communication difficulties they may experience and by providing communication partners as well. These data also indicate that while the good may outweigh the bad, there are still challenges to overcome and ways to support those on the spectrum when using CMC.

To start, both Greg and Steve point out advantages of using CMC. Greg points out that for him, communicating online is easier because of the varied ways one can respond, but also because writing responses is easier for him than formulating responses FTF. Steve mentions that using $\mathrm{CMC}$ provides opportunities of being able to connect with others on the spectrum and 
advocating for those with ASD. Greg notes that another benefit to CMC is that for some, online communities may be the only ones people with ASD participate in, and Steve also mentions the importance of using CMC to connect, particularly for those who may not have others to communicate with in physical proximity. These benefits directly relate to the data obtained in the survey. Survey participants overwhelmingly selected that having an opportunity to respond when they want along with having greater time to respond as benefits to CMC. Being a part of online communities was also noted by some participants as an important benefit to CMC. Advocating for self or others came up less than other benefits, but was still mentioned in the survey data of being of importance to at least two participants.

Challenges when using CMC were also brought up by both Greg and Steve. Greg in particular noted many challenges to using $\mathrm{CMC}$ to communicate, such as possible loss of privacy, online harassment, or even loss of employment because of online communication. Concerns of loss of privacy, or being 'outed' for having ASD was mentioned by both interviewees as a potential drawback of using $\mathrm{CMC}$, and were the most commonly selected answers by survey participants regarding challenges of using CMC.

Overall, answers provided through the interviews provided clarification on some of the concerns and benefits these specific individuals with ASD find when using CMC. Their responses, along with the responses collected on the survey, indicate that $\mathrm{CMC}$ is an important communication tool for those with ASD, so long as Internet safety is established. 


\section{CHAPTER V: DISCUSSION}

\section{Findings}

This study was conducted to determine what young adults with ASD perceive as the benefits and challenges of using $\mathrm{CMC}$, and the supports needed to access $\mathrm{CMC}$ not currently being utilized. The responses to the survey and interview questions indicate that young people with ASD utilize CMC for a variety of reasons. The data collected via the survey and interview

overall corroborate with previous studies done in this area. However, it is important to note that while the large picture results indicate similarities to previous studies, this study indicated that this population, like a neuro-typical population, is not homogeneous, and that there are differences even among this small sample size that indicate different attitudes and needs regarding young adults with ASD and CMC.

\section{Benefits}

It is somewhat unsurprising that those with ASD would find many benefits in using CMC to communicate. Challenges with FTF communication can include having to respond to people immediately, interpreting gestures and tone of voice, and make meaning out of nonverbal cues (Muller et al., 2008). These communication challenges can lead to difficulties with making friends and increase feelings of loneliness and isolation which ultimately leads to a poor quality of life (Jordan and Caldwell-Harris, 2012; Mazurek, 2013; Muller et al., 2008; Turner-Brown et al., 2008; van Asselt-Goverts et al., 2015; White et al., 2014). Challenges with FTF communication can include improvising dialogue, interpreting gestures and tone of voice, and making inferences (Muller et al., 2008). Previous studies have indicated that utilizing CMC is a way to reduce some of the challenges that people on the spectrum experience when communicating in person (Brownlow \& O’Dell, 2006; Muller et al., 2008; Watabe \& Suzuki, 
2015). Overall, results from this study indicate that there are more benefits than challenges when using CMC to communicate. The 21 respondents in this study selected 83 benefits to using CMC and only 41 challenges. Many of the benefits reported by participants in this study are similar to those reported in previous research.

Ease of responding. Gillespie-Lynch et al. (2014) found that people of all ages on the spectrum saw benefits of $\mathrm{CMC}$ such as ease of communicating, greater opportunities to interact with others, and freedom of self-expression. Barnes (2003) reported the opportunity to create purposeful and thoughtful messages as a benefit to CMC, while Braithwaite et al. (1999) noted the perks of longer wait time when communicating online. Responses in this study concur with these earlier findings. In this survey, $62 \%$ of respondents selected "being able to respond when you want (as opposed to immediately)" as a benefit of CMC. This was the mode of the data, followed by $54 \%$ of respondents who selected "greater amount of time to form a response" and $50 \%$ who selected "not having to read or interpret body language or nonverbal cues." These data indicate that people with ASD value the ease in responding to others that $\mathrm{CMC}$ provides, and qualitative data collected via survey also validates these notions. Of the 18 participants who provided information regarding the most important benefit of $\mathrm{CMC}, 50 \%$ indicated some sort of benefit related to timing and interpreting responses. One participant wrote "it's hard right away to think of the best way in saying a response to someone" indicating that the flexibility of being able to respond on one's own terms is a benefit to CMC. Almost all participants in this study selected email as a type of CMC they use; this type of asynchronous communication allows time to formulate response (Herring, 2011). Therefore, given the prevalence of email within our society and the benefits it offers those with ASD, it is unsurprising that email is being utilized by $90 \%$ of participants. 
Data collected from the survey in this study also support other previous assumptions about how this particular population could benefit from CMC. The ability to type responses instead of having to formulate verbal responses was noted as a benefit by Braithwaite et al. (1999) and was selected as a benefit by $52 \%$ of 21 respondents in this study; this also corroborates the idea that people with ASD may prefer written instead of spoken communication (Watabe \& Suzuki, 2015). Qualitative data collected from the survey and interview also validate these points. One participant wrote "being able to type/write responses instead of speaking, because I feel I come across much better in written communication than speaking" and another stated "when I talk the words are all jumbled and I do not make sense." This supports previous research done by Watabe and Suzuki (2015) who found that people with ASD reported they are able to express themselves more accurately online than FTF.

People with ASD also experience anxiety around communicating (Gillespie-Lynch et al., 2014; Mazurek, 2013). Gillespie-Lynch et al. (2014) found that people with ASD reported reduced anxiety when using $\mathrm{CMC}$ to communicate. Although this was not deliberately probed in this study, qualitative data collected by this survey indicate that this may be a by-product of these other benefits. One participant wrote "when I am having a conversation in person I feel pressured to respond right away" when naming the most important benefit of CMC. Another participant wrote "less stressful/more casual communication" when asked to name additional benefits when using the Internet to communicate. While not a specific benefit examined in this study, it is possible that with the reduction of stressors in FTF communicating, people with ASD experience less stress when using CMC. 
Connecting with others. Since its inception, people have been using CMC to share with others and keep in touch (Barnes, 2003). When compared to ease of responding, fewer people noted the ability to communicate with others as a benefit; $46 \%$ selected "opportunities to meet others you couldn't meet face to face" and $42 \%$ selected "being able to stay connected to family and friends." When asked to name the most important benefit of CMC, only three of the 18 participants responded staying connected to others was the most important benefit, and one of the 18 responded that the ability to meet others you couldn't meet face to face was the most important benefit. Although Jantz (2011) and Turner-Brown et al. (2008) found that people with ASD want to connect with and learn from one another, this was not reported as a benefit to CMC in this study. An additional difference in this study versus another is that quantitatively, one less person selected being able to stay connected versus opportunities to meet others you couldn't meet face to face while more people were reported to be connecting with people they know rather than meeting new people in a previous study (boyd \& Ellison, 2008). However, qualitatively, more people stated that staying in contact with others was the most important benefit to CMC than meeting others.

Herring (2011) found people who spend more time socializing online had more interactions offline. While this was not a direct probe of this study, qualitative survey data indicate that at least one participant made friends online and then met them offline. Additionally, $52 \%$ percent of participants indicated they used CMC to make plans to meet someone FTF at least once during the past two weeks, while $48 \%$ responded they had not done this at all. Many participants indicated they enjoy using CMC to interact with others. Previous studies have found that being part of an online community can increase social capital (Baker et 
al., 2013; Barak et al., 2008). While the effect of CMC on social capital was not directly studied in the current research, many participants noted the importance of having an online community. Additionally, Braithwaite et al. (1999) found that online communities and groups could be beneficial for those who are physically unable to travel to meet others. One participant in this study noted that (s)he is physically disabled, and "often confined to the house," which made CMC particularly valuable to this participant.

Special interests. Another benefit to using $\mathrm{CMC}$ is the ability to find people who share special interests. In this study, $62 \%$ of participants responded this is something they did at least once during the past two weeks, while $38 \%$ of participants reported not having done this at all in the past two weeks. Gillespie et al. (2014) found that when compared to Internet users not on the spectrum, those with ASD prefer to use the Internet to interact with others regarding special interests and experiences more, while people without ASD were found to prefer using SNS more than those on the spectrum. Qualitative survey data indicate that while it may not be the most important benefit in using $\mathrm{CMC}$, finding people who share special interests is of value to many participants. Of the 21 participants, 17 responded to the open ended question "what are the benefits you have experienced when using the Internet to communicate" and six of the 17 mention finding people with similar interests. One participant wrote "the internet is useful as an easy way to find other people that share interests."

Advocacy. Despite studies that indicate people with ASD may want to use the Internet to connect with others on the spectrum, either to learn from or share information, or for purposes of advocacy (Braithwaite et al., 1999; Brownlow \& O’Dell, 2006; Griffith et al., 2011), 45\% of participants indicated that they had not used CMC to talk to someone with ASD online in the past two weeks, and only $10 \%$ indicated this is something they had done every day of the past 
two weeks. Using CMC for self-advocacy, or the advocacy of others was somewhat more split; $38 \%$ of participants reported not having used CMC for purposes of advocacy over the past two weeks, while the remaining respondents indicated they had done it at least once. Qualitative survey responses were minimal on this issue; only two of 21 respondents mention advocacy for ASD as a benefit to CMC. Additionally, interview data verified that at least one participant feels that using CMC to advocate for others and encourage others to self-advocate is an important component of CMC. Finding people to communicate with who share similar experiences was selected as a challenge by three of 21 participants, one of whom indicated this is the biggest challenge of CMC by responding "finding people with similar experiences, because while I know I'm not alone with ASD, it is difficult to find those who know what it's like to have it."

Previous studies have also found that Facebook and LinkedIn are both used for their primary purposes of sharing information and networking by people with disabilities (Baker et al., 2013). Quantitative data obtained in this survey indicated that no participants were using advocacy websites or chatrooms, but qualitative data obtained via survey indicated that participants are using typical SNSs such as Twitter and Facebook to advocate for others.

\section{Challenges}

Despite the many benefits those with ASD find in using CMC, there are some challenges. Although challenges were reported at almost half the rate of benefits, there are concerns when using the Internet to communicate. Some of the main concerns regarded privacy, dealing with unkindness, and other drawbacks. Interestingly, the challenges were varied and unique across participants, with $24 \%$ of participants reporting no challenges in using $\mathrm{CMC}$ at all. 
Privacy. Concern regarding online privacy was the most commonly selected challenge in this survey, with $48 \%$ of participants selecting this as a concern; this was followed by concern about being taken advantage of online (33\%). These concerns are somewhat similar; people with ASD have concerns about disclosing their disability online and concern that they will be taken advantage of if they do. One participant wrote "people with autism may be highly vulnerable [to internet shaming] and also to cyber-bullying." The struggle to find a balance between maintaining privacy and sharing online has been documented in other studies (boyd \& Ellison, 2008), and is reiterated in this study using the qualitative survey data. When asked to select the greatest challenge in using $\mathrm{CMC}, 14$ participants responded, and the most common responses were concerns regarding privacy.

Shpigelman and Gill (2014) found that people have fear regarding disclosing their disability online, especially on SNSs such as Facebook where they may have difficulties navigating the privacy settings. Qualitative data from the interviews indicate that this is a concern for at least one participant who feels employers are looking at Facebook to check up on current or future employees. Results in this study are inconclusive regarding opinions on Facebook as $38 \%$ of participants in this study report not having a Facebook account, while another 38\% report checking Facebook every day. Qualitative data obtained from the survey is equally split, with one person writing "Facebook has also helped me reconnect with people from my past who share my values and interests," and another writing "I tend not to use social media except when absolutely necessary."

Disinhibition effect/misinterpretation. The disinhibition effect can lead to unkindness, or people saying things to someone online they wouldn't normally say FTF (Barak et al., 2008; Braithwaite et al., 1999). Dealing with people who are unkind, or experiencing the disinhibition 
effect is a concern for those with ASD when using CMC. This concern was noted in the quantitative survey results by way of 'other' and both in the qualitative survey and interview results. One participant wrote a detailed script about an unpleasant encounter he had with someone online, which resulted in the communication partner blocking him from further communication. Another participant stated that "you deal with people who try to provoke a response because they can."

People with ASD also are prone to misunderstanding the meaning of others, and to be misinterpreted themselves due to their difficulties with social communication. Again, this concern was noted in the quantitative results by way of 'other', and was noted in the qualitative survey and interview results. Participants in this study state that while there is the added benefit of reducing the nonverbal cues they must navigate when communicating FTF, satire and sarcasm are just as difficult to interpret online. Of 21 participants, 16 responded to a question to name challenges when using $\mathrm{CMC}$, and five wrote about misinterpreting the words of others and/or being misunderstood. One participant wrote "no one can hear my voice when I'm writing a blog post, and it might come across as conceited or angry even though I meant it matter-of-factly."

Additional drawbacks. There can be additional drawbacks when using $\mathrm{CMC}$ as well. For some, they may experience a feeling of negativity if their own life isn't perceived to be going as well as someone else's on SNS (Batenburg \& Das, 2015). One participant in this study stated "there have been times when I have felt left out, depressed or inadequate because I haven't been able to accomplish some of the successes my peers have." However, in this study, that is the only response that supported that previous research.

Another concern that has been documented in previous study is that $\mathrm{CMC}$ diminishes the amount of time for FTF communications (Chan, 2015). However, in this study only $19 \%$ of 
participants selected this as a challenge in using CMC, and it was mentioned just twice in the qualitative responses, with one person citing it was the greatest challenge, and another stating "I get in trouble from my dad when I spend too much time on the internet."

Overall, the challenges presented in the qualitative survey data are reflective of what a unique group of individuals completed this survey. While the challenges listed had some common themes, each specific drawback named was distinctly its own issue, lending credence to the idea that people with ASD cannot be treated as a homogeneous group and need supports that are individually tailored to each person's specific needs.

\section{Supports}

Data collected in this study indicate that there is some need for intervention on this topic. Although participants' responses clearly indicate a greater amount of benefits than challenges when utilizing $\mathrm{CMC}$, concerns were noted. Determining necessary supports for accessing websites that are not being currently utilized are as varied as the individuals who participated in this study. Previous research has indicated that having typically developing friends who can explain things to those with ASD (Sperry and Mesibov, 2005), and family, specifically mothers, are great support systems for those with ASD (Hurlbutt and Chalmers 2002). Others on the spectrum have reported that even the thought of having a support system available was helpful to them (Renty \& Roeyers, 2006).

Participants in this study were asked what supports they felt would be needed to minimize challenges in using CMC. Of the 21 participants, seven responded to this question. Overall, responding participants indicated they would like opportunities to access CMC that seem safe to them. Specific answers included:

- "list of trusted blogs" 
- "finding like minded chatrooms and blogs"

- "I need someone besides my mom to help me"

- "more social opportunities"

- "more opportunities for secure communications"

Additionally, participants in this study were asked to name supports or assistance they would need to access websites they are not currently utilizing, but that they would like to use. Of 21 participants, 14 responded. Of the 14 responses, only four named supports needed. These responses included:

- "I'm not sure how to do the security."

- "I would like to use dating websites, but I don't know any of the social rules for using them yet."

- "A helper one on one."

- "Where to find [assistance] and how to use this assistance."

The other ten responses either indicated that the participants couldn't think of any other websites they'd like to utilize, or that they would not need help navigating these sites. This is not terribly surprising, as this was a web-based survey. Participants who responded clearly can navigate the Internet, and may not need supports to access websites in the literal sense of the term. However, based on the qualitative data collected via survey and through interviews, it could be surmised that some young adults with ASD struggle with how to navigate the inferential part of communicating online, such as how much information is safe to reveal online, when it is ok to disclose a disability, or even seemingly explicit privacy settings.

Based on previous research and responses in this study, direct instruction given by a neuro-typical peer or family member may be helpful as people with ASD branch out and explore 
different areas of CMC. For those with ASD who do not indicate they need help, just knowing that a support system is available may be the key to exploring CMC as a viable communication tool.

\section{Conclusions}

Results from this study demonstrated that within this sample group of young adults with ASD there are more benefits to online communication than drawbacks. Although the need for some supports were mentioned in the study, most participants acknowledged that they feel as though they either did not need them or had no interest in pursuing CMC outside the realm of what they are currently utilizing. Based on these results (although more research with a larger sample size is needed) we can begin to assume that using CMC is a viable way for those with ASD, particularly young people who have been exposed to this technology all their lives, to communicate with others.

The data in this study also indicate that people with ASD want to connect with others, whether it be people they already know and want to strengthen ties with, or people they don't know who share similar interests and experiences. People with ASD have difficulties communicating with others FTF and with developing new relationships. The benefits provided by $\mathrm{CMC}$, such as the flexibility communicators have with responding and the ability to reach out to others across the world, are real assets to those on the spectrum who may not otherwise be able to develop or strengthen relationships when only afforded FTF opportunities. Supporting people with ASD, and teaching them the individualized skills needed to be confident while communicating online will help reduce many of the challenges participants noted in this study, namely fear of loss of privacy and being taken advantage of as a person with a disability. 


\section{Limitations}

There are a number of limitations to this study. To start, the sample size of 21 is low for a survey, as is two participants for interviews. This small sample size has to be considered when interpreting the results. However, given the characteristics of the population, this is not altogether surprising. People on the spectrum have difficulties with communication, and sharing information on a survey or via email may have seemed overwhelming or unimportant to someone who struggles with sharing thoughts, feelings, and ideas. They may not have wanted to risk disclosing their disability to a stranger, despite the assurances of anonymity. Also, although efforts were made to expose the survey to as many people as possible, it is reasonable to assume that there are people who would have been willing and able to complete the survey who never received the link. The age restrictions on the survey also limited the number of people who could participate; in fact, one participant contacted me regarding whether or not they could still participate despite being outside the age range of 18-30.

Another limitation is that people with ASD generally to have restricted interests. In the two interviews, information provided by the participants is presented as a summary of their responses. While their responses are unique unto them, it is also important to consider that their responses may not be indicative of a particularly strong belief, but of a fixated point of view due to the characteristics of ASD.

Additionally, the small sample size makes it difficult to generalize these responses to the population of young adults with ASD. This group of individuals not only had enough Internet and communication savvy to answer the questions in the survey, but to find the survey as well. The participants who completed the survey, and especially those individuals who answered the interview questions, likely felt that there was value to completing the study and sharing their 
opinions on using CMC. It is unsurprising that the results of this survey seem to indicate that they see many benefits to this type of communication. Additionally, it was assumed based on previous research that providing survey responses and interview responses via CMC such as email would be a preferred mode of communicating for those on the spectrum, which may not have been the case. Young adults with ASD who see more challenges than benefits likely either a) did not take the time to answer the survey questions or b) do not use the Internet in such a way that they encountered the survey at all.

This survey was distributed online and targeted people who use the Internet to communicate. By the very nature of distribution, people who responded to this study may already have a proclivity towards using the Internet to communicate. People who are already utilizing CMC may see more benefits in using it to communicate than those who are not currently communicating via the Internet. The information gleaned from this study should be examined with this knowledge in mind.

Survey design is another limitation in this study. Although the survey was designed with the target population in mind and piloted with people on the spectrum, it is impossible to anticipate the way all people will read and interpret the survey. Some questions yielded answers such as "I don't understand," or "This question is redundant." Despite efforts to make the survey clear for all participants, it is evident that some of the questions were not accessible to all participants.

Another limitation to this study is personal bias. My thoughts going into this study were, and remain, that $\mathrm{CMC}$ is a useful tool for those on the spectrum. This belief could not be separated from my interpretation of the data. Despite some of the challenges to using CMC, I genuinely believe that people with social communication difficulties can benefit from having 
some of the FTF barriers removed. Therefore, as I examined the qualitative data, my perceptions may have been clouded by this preconceived notion. Although there are ways to control for this, it remains a limitation of this study.

\section{Implications for Future Research}

This study, while providing a small picture of how young adults with ASD perceive utilizing the Internet, raises additional questions. The combination of the prevalence of CMC in our society with the number of children with ASD becoming adults leads to many opportunities to study how CMC can be utilized to help people with ASD with social and functional communication.

An online survey was chosen for this study because previous research indicated that people with ASD feel more confident communicating online than FTF (Watabe \& Suzuki, 2015), and because answering questions from home may make participants feel more comfortable when self-reporting (Jordan \& Caldwell-Harris, 2012). However, while 50 potential participants entered the survey, only 21 completed it. Although it is somewhat expected that some people on the spectrum may have difficulty answering the survey questions, it raises a larger issue. If we want to give a voice to those with ASD, what is the best modality for doing so? An online survey, followed by email interviews, was determined to be an appropriate modality for collecting information from this population. This decision was made based on knowledge of characteristics associated with ASD, such as difficulty with FTF social communication; future researchers may want to consider giving participants a choice in their method of responding. When Internet safety is taught, people are often cautioned to be weary of giving out information online. People with ASD are often rule followers who see things in black and white. If they are taught not to share personal information online, it is not unexpected that they may not be 
comfortable sharing their voice via an online survey. Many participants in this study indicated that one of the biggest challenges they face when using the Internet to communicate is either fear of loss of privacy or concern regarding being taken advantage. These concerns need to be addressed if people with ASD are going to become comfortable sharing information with researchers and practitioners online. If these concerns cannot be mitigated, future research may want to focus on the best way to obtain information from this population.

When conducting research with this population, we need to be circumspect about how we collect information. In his interview responses, Greg reported "it takes me about 2-3 or more hours to complete these responses. If I didn't do that, this response would be so [unintelligible] and unreadable, you wouldn't have asked for a $2^{\text {nd }}$ or $3^{\text {rd }}$ response." Reading this, it was apparent Greg had spent far more time answering the four questions sent to him than anticipated or expected, and that he was concerned about having his voice heard. He notes that he would not have been asked follow-up questions had he spent less time on his responses. Steve also mentioned in his responses that collecting and sharing information among people on the spectrum is an important issue, and that obtaining this information to promote advocacy should be explored. To this end, how do we get the information that people on the spectrum want to share with us without placing demands upon them that are both time consuming and (presumably) mentally exhausting?

Additionally, Greg responded to another question by answering "I don't feel the need to describe the financial issues autistic people face." This comment indicates a deeper seeded issue that is outside the scope of the current study, but may warrant attention by future researchers. Are these financial issues due to under or unemployment, or because of issues of money management, or a different reason altogether? Greg also mentioned that one of the benefits to 
$\mathrm{CMC}$ is that "online you can check over your grammar, spelling, sources, and facts to have a solid argument. I believe after doing this long enough you can instill confidence where it was once lost." As people with ASD regularly have difficulties with FTF interactions, future research is needed to see if using online communication can help build confidence in social communication skills, and then transfer that confidence to a FTF setting. Although previous research has shown that transferring skills is not always a viable solution for those with ASD (Fletcher-Watson et al., 2013; Howlin \& Yates, 1999), however others have noted that social skills taught in a literal context could be utilized as a resource (Sperry and Mesibov, 2005) and that positive social interactions tend to build confidence, leading to further social interactions (Koegel, 2007).

Greg's responses also indicate a need to further investigate how people with ASD feel they are perceived by others. If people with ASD are concerned that sharing their experiences and connecting online may prohibit them from finding and maintaining employment, then this is an issue that should be explored by future researchers to determine if this is a concern shared by many in the population. It also demonstrates a need for research with employers to determine their attitudes of having people with ASD in the workplace. Indeed, previous research indicates a fear that lack of understanding about ASD may lead to unemployment (Griffith et al., 2011). Additionally, Greg states "there are people in this world that target autistics, as they think we are against their political or religious beliefs," while another participant who responded to the survey wrote "people often can't tell that you're autistic so [you're] not judged right away" as a benefit when using CMC. This statement indicates that Greg, and perhaps others, feel as though they would be rejected or even harmed for having a disability. Steve's answers also indicated a concern that if potential employers know a candidate has ASD, then this knowledge may work 
against them when seeking future employment. Greg's answers also indicated that his perception is that people with ASD are not taken seriously, which is another possible area of research to explore.

More research is also needed to determine how people with ASD choose and utilize social networking sites to connect with others. Many participants in this study indicated they found online communities (often unrelated to disability) and that these communities contain their closest friends. Some participants even noted that they had never met their friends FTF, or that they have only met their friends in person one time. The importance of these online communities and how people find them requires more research. Online ASD communities are also mentioned by both interviewees as important connections for those with ASD. Previous research indicates that people with ASD want to connect and have friends, but often find themselves socially isolated (Hendricks and Wehman, 2009). Additionally, previous research states that young men with ASD are interested in romantic relationships (Hellemans et al., 2007), and three of the 21 participants in this study responded they are using dating websites. As this study has established that people with ASD see more benefits to challenges when using the Internet to communicate, future studies may want to focus on how using CMC can increase quality of life and reduce loneliness in those with ASD.

\section{Implications for Future Practice}

Participants in this study noted challenges in using CMC. Specifically, people with ASD are concerned about having their privacy violated and of being taken advantage. Suggestions by participants in this study to help mitigate these challenges include desires for lists of "trusted" websites and explicit instruction or help in using the Internet; future researchers may want to study how those with ASD are taught to use CMC. Going further, teachers and advocates should 
perhaps begin to consider teaching online social norms or 'rules' as part of functional communication as part of independent living. Teaching Internet safety in schools, as well as how to access various networking sites may ease some of the difficulties as students begin to age out of school. Additionally, studying and learning more about the confidence of teachers and related service providers to teach these skills may be warranted. Going forward, those who work with individuals on the spectrum may be called upon as a resource to help young people begin navigating the social world of the Internet. As many people with ASD are not able to transfer theoretical skills into real-life situations (Turner-Brown et al., 2008), more research in the area of explicit instruction in utilizing CMC for people with ASD is certainly warranted. 


\section{REFERENCES}

Adreon, D., \& Durocher, J. S. (2007). Evaluating the college transition needs of individuals with high-functioning autism spectrum disorders. Intervention in School and Clinic, 42, 271-279. doi:10.1177/10534512070420050201

Baker, P. M. A., Bricout, J. C., Moon, N. W., Coughlan, B., \& Pater, J. (2013). Communities of participation: A comparison of disability and aging identified groups on Facebook and LinkedIn. Telematics and Informatics, 30, 22-34. doi: 10.1016/j.tele.2012.03.004

Barak, A., Boniel-Nissim, M., \& Suler, J. (2008). Fostering empowerment in online support groups. Computers in Human Behavior, 24, 1867-1883. doi: 10.2026/j.ch.b.2008.02.004

Barnes, S. B. (2003). Computer-mediated communication: Human-to-human communication across the Internet. Boston, MA: Pearson Education, Inc.

Barnhill, G. (2001). What is Asperger syndrome. Intervention in School and Clinic, 36(5), 25965. Retrieved from ERIC database.

Barnhill, G. (2007). Outcomes in adults with Asperger syndrome. Focus on Autism and Other Developmental Disabilities, 22(2), 116-126. doi:10.1177/10883576070220020301

Batenburg, A. \& Das, E. (2015). Virtual support communities and psychological well-being: The role of optimistic and pessimistic social comparison strategies. Journal of ComputerMediated Communication, 20, 585-600. doi: 10.1111/jcc4.12131

Benford, P. (2008). The use of Internet-based communication by people with autism (Doctoral dissertation). Retrieved from ProQuest. (http://eprints.nottingham.ac.uk/10661/1/thesis_post_viva_version_2.pdf) 
boyd, d. m. \& Ellison, N. B. (2008). Social network sites: Definition, history, and scholarship. Journal of Computer-Mediated Communication, 13, 210-230. doi: 10.1111/j.10836101.2007.00393.x

Braithwaite, D. O. \& Waldron, V. R. (1999). Communication of social support in computermediated groups for people with disabilities. Health Communication, 11(2), 123-151.

Brandtzaeg, P. B. (2012). Social networking sites: Their users and social implications - A longitudinal study. Journal of Computer-Mediated Communication, 17, 467-488. doi: 10.1111/j.1083-6101.2012.01580.x

Brownlow, C. \& O’Dell, L. (2006). Constructing an autistic identity: AS voices online. Mental Retardation, 44(5), 315-321.

Buntinx, W. H. E. \& Schalock, R. L. (2010). Models of disability, quality of life, and individualized supports: Implications for professional practice in intellectual disability. Journal of Policy and Practice in Intellectual Disabilities, 7(4), 283-294.

Center for Disease Control and Prevention (2015). Prevalence of Autism Spectrum Disorders. Retrieved from http://www.cdc.gov/mmwr/preview/mmwrhtml/ss5810a1.htm

Chan, M. (2015). Multimodal connectedness and quality of life: Examining the influences of technology adoption and interpersonal communication on well-being across the life span. Journal of Computer-Mediated Communication, 20, 3-18. doi: 10.1111/jcc4.12089

Cheung, Y. W. Mok, B.-H., Cheung, T.-S. (2005). Personal empowerment and life satisfaction among self-help group members in Hong Kong. Small Group Research, 36(3), 354-377. doi: $10.1177 / 1046496404272510$

Creswell, J. W. (2014). Research design: Qualitative, quantitative, \& mixed method approaches ( $4^{\text {th }}$ ed.). [Kindle Version]. Retrieved from Amazon.com 
Fletcher-Watson, S., Leekam, S. R., \& Findlay, J. M. (2013). Social interest in high-functioning adults with autism spectrum disorders. Focus on Autism and Other Developmental Disabilities, 28(4), 222-229. doi: 10.1177/1088357613480829

Gavetter, F. J. \& Wallnau, L. B. (2013). Statistics for the behavioral sciences, $9^{\text {th }}$ edition. Belmont, CA: Wadsworth, Cengage Learning.

Genderqueer. (2004). In Urban Dictionary online. Retrieved from http://www.urbandictionary.com/define.php?term=genderqueer

Gillespie-Lynch, K., Kapp, S. K., Shane-Simpson, C., Smith, D. S., \& Hutman, T. (2014). Intersections between the autism spectrum and the Internet: Perceived benefits and preferred functions of computer-mediated communication. Intellectual and Developmental Disabilities, 52(6), 456-469. doi: 10.1352/1934-9556-52.6.456

Goodwin, M. S. (2008). Enhancing and accelerating the pace of autism research and treatment. Focus on Autism and Other Developmental Disabilities, 23(2), 125-128. doi: $10.1177 / 1088357608316678$

Green-Hamann, S. \& Sherblom, J. C. (2014). The influences of optimal matching and social capital on communicating support. Journal of Health Communication, 19, 1130-1144. doi: $10.1080 / 10810730.2013 .864734$

Griffith, G. M., Totsika, V., Nash, S., \& Hastings, R. P. (2011). 'I just don't fit anywhere’: Support experiences and future support needs of individuals with Asperger syndrome in middle school. Autism, 16(5), 532-546. doi: 10.1177/1362361311405223

Gutstein, S., \& Whitney, T. (2002). Asperger syndrome and the development of social competence. Focus on Autism and Other Developmental Disabilities, 17(3), 161-71. Retrieved from ERIC database. 
Hellemans, H., Colson, K., Verbraeken, C., Vermeiren, R., \& Deboutte, D. (2007). Sexual behavior in high-functioning male adolescents and young adults with autism spectrum disorder. Journal of Autism and Developmental Disorders, 37(2), 260-269. doi:10.1007/s10803-006-0159-1

Hendricks, D.R., \& Wehman, P. (2009). Transition from school to adulthood for youth with autism spectrum disorders: Review and recommendations. Focus on Autism and Other Developmental Disabilities, 24, 77-88. doi:10.1177/1088357608329827

Herring, S. C. (2011). Computer-mediated conversation: Introduction and overview. Language@Internet, 8,1-12.

Hillier, A., Fish, T., Cloppert, P., \& Beversdorf, D. (2007). Outcomes of a social and vocational skills support group for adolescents and young adults on the autism spectrum. Focus on Autism and Other Developmental Disabilities, 22(2), 107-115. Retrieved from ERIC database.

Howlin, P. \& Yate, P. (1999). The potential effectiveness of social skills groups for adults with autism. Autism, 3(3), 299-307. doi: 10.1177/1362361399003003007

Hume, K., Loftin, R., \& Lantz, J. (2009). Increasing independence in autism spectrum disorders: A review of three focused interventions. Journal of Autism and Developmental Disorders, 39(9), 1329-1338. doi:10.1007/s10803-009-0751-2

Hurlbutt, K., \& Chalmers, L. (2002). Adults with autism speak out: Perceptions of their life experiences. Focus on Autism and Other Developmental Disabilities, 17(2), 103-111. doi:10.1177/10883576020170020501

Jantz, K. M. (2011). Support groups for adults with Asperger syndrome. Focus Autism and Other Developmental Disabilities, 26(2), 119-128. doi: 10.1177/1088357611406903 
Jennes-Coussens, M., Magill-Evans, J., \& Koning, C. (2006). The quality of life of young men with Asperger syndrome: A brief report. Autism, 10(4), 403-414.

Johnson, R. B. (1997). Examining the validity structure of qualitative research. Education, 118, 282-292.

Jordan, C. J. \& Caldwell-Harris, C. L. (2012). Understanding differences in neurotypical and autism spectrum special interests through Internet forums. Intellectual and Developmental Disabilities, 50(5), 391-402. doi: 10.1352/1934-9556-50.5.391

Kandalaft, M. R., Didehbani, N., Krawczyk, D. C., Allen, T. T., \& Chapman, S. B. (2013). Virtual reality social cognition training for young adults with high-functioning autism. Journal of Autism and Developmental Disorders, 43, 34-44. doi: 10.1007/s10803-012$1544-6$

Koegel, R. L. (2007). Social development in individuals with high functioning autism and Asperger disorder. Research \& Practice for Persons with Severe Disabilities, 32(2), 140141.

Kuo, M. H., Orsmond, G. I., Coster, W. J., \& Cohn, E. S. (2013). Media use among adolescents with autism spectrum disorder. Autism, 18(8), 914-923. doi: 10.1177/1362361313497832

Lewis, S. E. (2006). Recognition of workplace bullying: A qualitative study of women targets in the public sector. Journal of Community and Applied Social Psychology, 16, 119-135. doi: $10.1002 /$ casp. 850

Ley, B. L. (2007). Vive les roses! The architecture of commitment in an online pregnancy group and mothering group. Journal of Computer-Mediated Communication, 12, 1388-1408. doi: 10.1111/j.1083-6101.2007.00378.x 
MacLeod, A. \& Johnston, P. (2007). Standing out and fitting in: A report on a support group for individuals with Asperger syndrome using a personal account. British Journal of Special Education, 34(2), 83-88.

Mazurek, M. O. (2013). Social media use among adults with autism spectrum disorders. Computers in Human Behavior, 29, 1709-1714. doi: 10.1016/j.chb.2013.02.004

Mazurek, M. O. \& Wenstrup, C. (2012). Television, video game and social media use among children with ASD and typically developing siblings. Journal of Autism and Developmental Disorders, 43, 1258-1271. doi: 10.1007/s10803-012-1659-9

Muller, E., Schuler, A., \& Yates, G. B. (2008). Social challenges and supports from the perspective of individuals with Asperger syndrome and other autism spectrum disabilities. Autism, 12(2), 173-190.

Ofoegbu, N. E. \& Azarmsa, R. (2010). Impact of the special education vocational education program (VEP) on student career success. International Journal of Special Education, 25(2), 34-46.

Ong, C.-S., Chang, S.-C., \& Wang, C.-C. (2011). Comparative loneliness of users versus nonusers of online chatting. Cyberpsychology, Behavior, and Social Networking, 14, 35 40. doi: $10.1089 /$ cyber.2009.0321

Onwuegbuzie, A. J. \& Teddlie, C. (2003). A framework for analyzing data in mixed methods research. In A. Tashakkori \& C. Teddlie (Eds.), Handbook of Mixed Methods in Social \& Behavioral Research (pp. 351-383). Thousand Oaks, CA: Sage Publications.

Orchard, L. J., Fullwood, C., Galbraith, N., \& Morris, N. (2014). Individual differences as predictors of social networking. Journal of Computer-Mediated Communication, 19, 388402. doi: $10.1111 / \mathrm{jcc} 4.12068$ 
Orsmond, G., Krauss, M., \& Seltzer, M. (2004). Peer relationships and social and recreational activities among adolescents and adults with autism. Journal of Autism and Developmental Disorders, 34(3), 245-256. Retrieved from ERIC database.

Renty, J. \& Roeyers, H. (2006). Quality of life in high-functioning adults with autism spectrum disorder. Autism, 10(5), 511-524.

Roscoe, W. (2010). Who are the two spirits? Retrieved from http://www.willsworld.org/twospiritq-a.html

Ruppel, E. K. \& Burke, T. J. (2014. Complementary channel use and the role of social competence. Journal of Computer-Mediated Communication, 20, 37-51. doi: $10.1111 /$ jcc4.12091

Saldana, J. (2016). The coding manual for qualitative researchers [Kindle Version]. Retrieved from Amazon.com

Sandelowski, M. (2003). Tables or tableaux? The challenges of writing and reading mixed methods studies. In A. Tashakkori \& C. Teddlie (Eds.), Handbook of Mixed Methods in Social \& Behavioral Research (pp. 321-350). Thousand Oaks, CA: Sage Publications.

Shpigelman, C. N. \& Gill, C. J. (2014). Facebook use by persons with disabilities. Journal of Computer Mediated Communication, 19, 610-624. doi: 10.1111/jcc4.12059

Sperry, L. A. \& Mesibov, G. B. (2005). Perceptions of social challenges of adults with autism spectrum disorder. Autsim, 9(4), 362-376.

Sum, S., Mathews, M. R., Pourghasem, M., \& Hughes, I. (2008). Internet technology and social capital: How the Internet affects seniors' social capital and wellbeing. Journal of Computer-Mediated Communication, 14, 202-220. doi: 10.1111/j.1083$6101.2008 .01437 . \mathrm{x}$ 
Turner-Brown, L., Perry, T., Dichter, G., Bodfish, J., \& Penn, D. (2008). Brief report: Feasibility of social cognition and interaction training for adults with high functioning autism. Journal of Autism and Developmental Disorders, 38(9), 1777-1784. doi:10.1007/s10803008-0545-y

van Asselt-Goverts, A. E., Embregts, P. J. C. M., Hendriks, A. H. C., Wegman, K. M., \& Teunisse, J. P. (2015). Do social networks differ? Comparison of the social networks of people with intellectual disabilities, people with autism spectrum disorders, and other people living in the community. Journal of Autism and Developmental Disorders, 45, 1191-1203. doi: 10.1007/s10803-014-2279-3

van der Aa, C., Pollmann, M. M. H., Plaat, A., \& van der Gaag, R. J. (2016). Computer-mediated communication in adults with high-functioning autism spectrum disorders and controls. Research in Autism Spectrum Disorders, 23, 15-27.

VanBergeijk, E., Klin, A., \& Volkmar, F. (2008). Supporting more able students on the autism spectrum: College and beyond. Journal of Autism and Developmental Disorders, 38, 1359-1370. doi:10.1007/s10803-007-0524-8

Walther, J. B. \& Burgoon, J. K. (1992). Relational communication in computer-mediated interaction. Human Communication Research, 19(1), 50-88. doi: 10.1111/j.14682958.1992.tb00295.x

Watabe, T. \& Suzuki, K. (2015). Internet communication of outpatients with Asperger's disorder or schizophrenia in Japan. Asia-Pacific Psychiatry, 7, 27-35.

White, S. W., Scarpa, A., Conner, C. M., Maddox, B. B., \& Bonete, S. (2014). Evaluating change in social skills in high-functioning adults with autism spectrum disorder using a 
laboratory-based observational measure. Focus on Autism and Other Developmental Disorders, 30(1), 3-12. doi: 10.1177/1088357614539836

Whitehouse, A. J. O., Watt, H. J., Line, E. A., \& Bishop, D. V. M. (2009). Adult psychosocial outcomes of children with specific language impairment, pragmatic language impairment and autism. International Journal of Language \& Communication Disorders, 44(4), 511528. doi: $10.1080 / 13682820802708098$

Willis, G. B. (1999). Cognitive interviewing: A "how to" guide. Short course presented at the 1999 Meeting of the American Statistical Association.

Wolfe, P., Condo, B., \& Hardaway, E. (2009). Sociosexuality education for persons with autism spectrum disorders using principles of applied behavior analysis. TEACHING Exceptional Children, 42(1), 50-61. Retrieved from ERIC database. 


\section{APPENDIX A: INFORMED CONSENT AND SURVEY QUESTIONS}

You are asked to participate in a research study being completed by Laura Massier, a doctoral candidate at Illinois State University under the supervision of Dr. Debbie Shelden. Participation in this study is being requested of young adults with autism spectrum disorder (ASD), ages 1830. Please read the following information carefully before deciding whether or not to participate. Your participation in this study is completely voluntary, and can be retracted at any time by ending the survey. If you have any questions or concerns, please contact Laura Massier or Dr. Debbie Shelden. This survey should take between 15-20 minutes to complete.

\section{Purpose of Study}

This study is being conducted to determine the perceived benefits, challenges, and support needs of young adults with ASD regarding computer-mediated communication. Although there have been many studies completed regarding communication challenges of those with ASD, there is less data available on how people between the ages of 18-30 with ASD use the Internet to communicate. This study aims to help fill that gap by providing information directly from young adults on the spectrum regarding their use of the Internet.

\section{Procedures}

Participants for this study will be asked to complete an online survey. The survey should take approximately 15-20 minutes.

\section{Privacy and Confidentiality}

This survey can be done anonymously. You may wish to provide your email at the end of the survey if you wish to be contacted for a follow-up interview or receive information regarding the outcome of this study. Any identifying information will be kept confidential through use of pseudonyms, coding, and secure storage of data. After five years, all raw data for this survey will be destroyed.

\section{Participation and Withdrawal}

This survey is completely voluntary. If you choose not to participate, there will be no adverse effect on you. If you begin the survey and choose not to complete it, there will be no penalty to you. You may withdraw your consent for this research at any time by exiting the survey with no penalty to you. You may skip any question on the survey if you are not comfortable answering it.

\section{Potential Risks to You}

There are minor risks involved in participating in this survey. You will be asked to disclose your disability to the researchers. However, this data will be kept confidential by the researchers, and you will not be asked to provide your name. You may feel uncomfortable during the survey 
about reporting your Internet usage. If needed, you may skip any question that gives you discomfort. Some direct quotations will be used in this study. However, no identifiers will be attached to the quotations that would allow the participant's identity to be revealed.

\section{Potential Benefit to You}

There is no direct benefit to you in participating in this survey. However, your response will provide information that may be helpful to others with ASD, researchers, families, therapists, and educators.

If you have any questions concerning the research study, please call Laura Massier at [redacted] or by email at lamassi@ilstu.edu or Dr. Debbie Shelden at 309.438.5661 or by email at dlsheld@,ilstu.edu.

If you have any questions about your rights as a participant in this research, or if you feel you have been placed at risk, you can contact the Research Ethics \& Compliance Office at Illinois State University at 309.438.2529 and/or rec@ilstu.edu

Thank you,

Laura Massier

Confirmation of Participant

By clicking "yes" I acknowledge that I've been provided all relevant information regarding this study and consent to participate in this research.

1. Do you wish to continue with the survey?

a. Yes

b. No

Qualifying Questions

2. Have you ever been diagnosed on the autism spectrum?
a. Yes
b. No

3. Who made your diagnosis?
a. doctor
b. psychiatrist
c. school psychologist
d. self-diagnosed
e. other: 
f. prefer not to answer

4. Please select the age group that best describes you:
a. younger than 18
b. $18-21$
c. $22-24$
d. $25-27$
e. $28-30$
f. Over 30

5. Do you use the Internet to communicate with others?
a. Yes
b. No

\section{Demographic Questions}

6. What is your gender?

7. Which of the following best describes your ethnic background? Choose all that apply.
a. Caucasian
b. Hispanic
c. Asian
d. African-American
e. Native American
f. Pacific Islander
g. Other, please specify
h. Prefer not to answer

8. What is your marital status?
a. Married
b. Single, never married
c. Divorced
d. Widowed
e. Living with a partner
f. Other, please specify
g. Prefer not to answer

9. Which of the following best describes your living situation? Choose all that apply.
a. I live with my parents.
b. I live with my adult sibling.
c. I live on my own. 
d. I live in a supported living situation (i.e. someone assists you with daily living activities).

e. I live with a roommate.

f. I live in a group home.

g. I live with my partner or spouse.

h. I live with my children.

i. I live with my partner or spouse and our children.

j. Other, please specify

k. I prefer not to answer.

10. Which of the following best describes your current completed level of education?
a. High school student
b. High school graduate
c. Vocational or technical training
d. Associate's degree (2 years of college)
e. Bachelor's degree (4 years of college)
f. Master's degree
g. Doctoral degree
h. Other, please specify
i. Prefer not to answer

11. Which of the following describes your employment status? Choose all that apply.
a. I work full time.
b. I work part time.
c. I am unemployed.
d. I am looking for work.
e. I have multiple jobs.
f. I volunteer.
g. I receive disability services/pay
h. Other, please specify.
i. I prefer not to answer.

\section{Computer Mediated Communication}

12. Which of the following Computer Mediated Communication do you use to communicate with family, friends, or others? Choose all that apply.
a. Email
b. Social networking sites
c. Blogs
d. Dating websites
e. Advocacy websites (ex: such as autismadvocacy.org; wrongplantet.net) 
f. Advocacy chatrooms (ex: chatroom on wrongplanet.net)

g. Special interest websites (i.e. websites to learn about topics you enjoy)

h. Special interest chatrooms (i.e. spaces to chat with people about topics you enjoy)

i. Other, please specify.

j. I prefer not to answer.

13. In the past two weeks, how often have you used the following computer mediated communication tools (not at all, at least once, 5-10 times, more than 10 times, everyday)?
a. Interact with people you already know
b. Meet and interact with new people
c. Find someone to talk to who has ASD
d. Advocate for yourself or others
e. Participate in an online discussion
f. Read other people's posts
g. Look at other people's pictures
h. Find people with similar interests
i. Other:

14. In the past two weeks, how many times have you used the Internet to (not at all, at least once, 5-10 times, everyday):

j. Make plans to meet someone face-to-face

k. Look for employment opportunities

15. If you have an account for any of these sites, how many times have you logged into these sites in the past two weeks (no account, $0,1-5,6-10,11-15,16-20$, more than 20)?
a. Twitter
b. Facebook
c. MySpace
d. Google+
e. LinkedIn
f. Instagram
g. Tumblr
h. Snapchat

16. Which of these, if any, do you perceive as a benefit to communicating with people online? Select all that apply. 
a. Greater amount of time to form a response

b. Being able to respond when you want (as opposed to immediately)

c. The opportunity to meet others you couldn't meet face to face

d. Not having to read or interpret body language or nonverbal cues

e. Being able to stay connected to family and friends

f. Being able to type or write responses instead of speaking

g. Other, please specify

h. I prefer not to answer

17. Of the benefits you chose above, which do you perceive to be the most important benefit?

18. Which of these, if any, do you perceive as challenges to communicating with people online? Choose all that apply.

a. Concern about online privacy

b. Finding people to communicate with who share similar interests

c. Finding people to communicate with who share similar experiences

d. Navigating different websites

e. Concern about being taken advantage of while online

f. Concern that spending too much time online means less time for your offline relationships

g. Other, please specify

h. None

i. I prefer not to answer

19. Of the challenges you chose above, which do you perceive to be the greatest challenge in communicating with people online, and why?

a. Follow up question: What supports would you need to minimize this challenge?

20. Describe your overall experience with using the Internet to communicate.

21. What are the benefits you have experienced when using the Internet to communicate?

22. What are the challenges or drawbacks you experienced when using the Internet to communicate?

23. If there are computer mediated communication tools or websites you are not currently using that you would like to use, what support or assistance would you need in order to access these websites?

24. Please share with me any additional information regarding your experiences using online communication. 
25. Are you interested in being contacted via for a follow-up email interview for this study? (an answer of YES leads the participant to Question 26, an answer of NO thanks the participant for their time and ends the survey.)

26. Please provide your email address.

27. Please confirm your email address. 


\section{APPENDIX B: INFORMED CONSENT AND INITIAL INTERVIEW QUESTIONS}

\section{Informed Consent}

\section{Perceptions of Young Adults with ASD regarding computer mediated communication}

You are invited to participate in a research study being completed by Laura Massier, a doctoral candidate at Illinois State University under the supervision of Dr. Debbie Shelden. Participation in this study is being requested of young adults with autism spectrum disorder (ASD), ages 1830. Please read the following information carefully before deciding whether or not to participate. Your participation in this study is completely voluntary, and can be retracted at any time by ending the survey. If you have any questions or concerns, please contact Laura Massier or Dr. Debbie Shelden. This interview will be completed over a series of 4 emails, to be completed at the discretion of the participant.

\section{Purpose of Study}

This study is being conducted to determine the perceived benefits, challenges, and support needs of young adults with ASD regarding computer-mediated communication. Although there have been many studies completed regarding communication challenges of those with ASD, there is less data available on how people between the ages of 18-30 with ASD use the Internet to communicate. This study aims to help fill that gap by providing information directly from young adults on the spectrum regarding their use of the Internet.

\section{Procedures}

Participants for this study will be asked to answer questions regarding the information they provided on an electronic survey. They will receive a series of 4 emails with 3-4 open ended questions in each email.

\section{Privacy and Confidentiality}

Email addresses will be connected to pseudonyms, and all identifying information will be kept confidential through use of pseudonyms, coding, and secure storage of data. After five years, all raw data for this survey will be destroyed.

\section{Participation and Withdrawal}

The interviews are completely voluntary. If you choose not to participate, there will be no adverse effect on you. If you begin the interview process and choose not to complete it, there will be no penalty to you. You may withdraw your consent for this research at any time by 
notifying the researcher that you no longer with to participate via email. You may choose not to answer any of the specific interview questions with no penalty to you.

\section{Potential Risks to You}

There are minor risks involved in participating in this interview. You will be asked to disclose your disability to the researchers. However, this data will be kept confidential by the researchers, and you will not be asked to provide your name. You may feel uncomfortable during the interview about reporting your Internet usage. If needed, you may skip any question that gives you discomfort. Some direct quotations will be used in this study. However, no identifiers will be attached to the quotations that would allow the participant's identity to be revealed. Additionally, email is not a secure medium. Emails can be sent to the wrong person or forwarded on to other people. However, an email address for the researcher will be set up specifically for the use of conducting these interviews to minimize any inadvertent communications from this email address. Prior to beginning the interview questions, you will be contacted by the researchers using the interview email address to ensure you have the correct address. After the interview data has been collected, the email account will be deleted. Only the researchers will have access to the email account.

\section{Potential Benefit to You}

There is no direct benefit to you in participating in this survey. However, your response will provide information that may be helpful to others with ASD, researchers, families, therapists, and educators.

If you have any questions concerning the research study, please call Laura Massier at [redacted] or by email at lamassi@ilstu.edu or Dr. Debbie Shelden at 309.438.5661 or by email atdlsheld@ilstu.edu.

If you have any questions about your rights as a participant in this research, or if you feel you have been placed at risk, you can contact the Research Ethics \& Compliance Office at Illinois State University at 309.438.2529 and/or rec@ilstu.edu

Thank you,

Laura Massier

Confirmation of Participant

By responding to this email, I agree to participate in the study and acknowledge that I've been provided all relevant information regarding this study and consent to participate in this research. 
(These questions were proposed and then revised based on the data from the survey.)

1. What is your preferred method of communication?

2. How often do you use the Internet to communicate online?

3. Who do you communicate with online?

4. What types of CMC do you use? What made you choose those channels?

5. What do you like about $\mathrm{CMC}$ ?

6. What do you dislike about $\mathrm{CMC}$ ?

7. What CMC would you like to use that you are not currently using?

8. Have you ever, or are you interested in, communicating with others with ASD online?

9. What are your interests? How have you used the Internet to explore those interests or connect with others who share those interests?

10. Have you ever utilized an online support group? Describe this experience. 


\section{APPENDIX C: INTERVIEW QUESTIONS}

Question Set 1 (sent to all participants):

1. Can you describe how you currently use CMC (computer-mediated communication)?

2. Describe your primary purpose for using email (ex: work, leisure, etc).

3. If you don't already do this, would you consider using social media to connect with others on the autism spectrum? Why or why not? If you currently do, please share these experiences.

4. If you have a social media account on a site such as Twitter or Facebook, how did you decide to set up these accounts? What features do they have that you enjoy using?

Question Set 2 (Steve):

1. Do you feel using Facebook has strengthened any of your existing relationships, or helped you develop new ones?

2. Are there any ASD specific websites you visit? If so, what are they?

3. You mentioned you may sign up for LinkedIn, but are resisting - why is that?

4. Can you tell me more about the Authors with Autism group you facilitate? Is it online, or face-to-face?

Question Set 2 (Greg):

1. I am not familiar with City Data - can you tell me more about it?

2. Your responses indicated that you feel people with ASD face many challenges in socializing online, but that it is necessary to socialize to prevent skill regression. Do you prefer to socialize with people online or face-to-face, or in another format? Why?

3. You mention that social media is an "invaluable tool" - how has using CMC affected your ability to develop new relationships and strengthen existing ones?

4. You also mentioned that you worry about employers researching employees online. How do you find sites that you trust?

Question Set 2 (not answered by participant):

1. Has using computer mediated communication affected your ability to develop new relationships and strengthen existing ones? If so, how? 
2. What websites do you enjoy using? How do you find sites that are interesting to you?

3. Have you ever made a friend through a website or the Internet?

Question Set 3 (Steve):

1. Do you ever anticipate using Facebook or other social media to connect more with others, either on or off the spectrum? Why or why not?

2. You read a lot of articles and share information in an online journal - how important is it to you to share your ASD experience with others online?

3. Do you ever encounter people online who are unkind? If so, how do you deal with this?

4. How do you decide how much personal information to disclose online?

\section{Question Set 3 (Greg):}

1. You mention that people can have online autistic communities. How can someone find an online autistic community? When you communicate with people online, are you typically communicating with the same people over and over again, or is the community constantly changing?

2. When communicating with people online, how do you decide how much personal information to disclose to others?

3. How do you deal with people who are cruel or unkind online?

4. Is there anything else you want to tell me about communicating online? 